\title{
Oxygen/Glucose Deprivation Induces a Reduction in Synaptic AMPA Receptors on Hippocampal CA3 Neurons Mediated by mGluR1 and Adenosine $\mathrm{A}_{3}$ Receptors
}

\author{
Siobhan H. Dennis, ${ }^{1}$ Nadia Jaafari, ${ }^{2}$ Helena Cimarosti, ${ }^{2,3}$ Jonathan G. Hanley, ${ }^{2}$ Jeremy M. Henley, ${ }^{2}$ and Jack R. Mellor ${ }^{1}$ \\ Medical Research Council Centre for Synaptic Plasticity, ${ }^{1}$ School of Physiology and Pharmacology and ${ }^{2}$ School of Biochemistry, University of Bristol, Bristol \\ BS8 1TD, United Kingdom, and ${ }^{3}$ School of Pharmacy, University of Reading, Reading RG6 6UB, United Kingdom
}

\begin{abstract}
Hippocampal CA1 pyramidal neurons are highly sensitive to ischemic damage, whereas neighboring CA3 pyramidal neurons are less susceptible. It is proposed that switching of AMPA receptor (AMPAR) subunits on CA1 neurons during an in vitro model of ischemia, oxygen/glucose deprivation (OGD), leads to an enhanced permeability of AMPARs to $\mathrm{Ca}^{2+}$, resulting in delayed cell death. However, it is unclear whether the same mechanisms exist in CA3 neurons and whether this underlies the differential sensitivity to ischemia. Here, we investigated the consequences of OGD for AMPAR function in CA3 neurons using electrophysiological recordings in rat hippocampal slices. Following a 15 min OGD protocol, a substantial depression of AMPAR-mediated synaptic transmission was observed at CA3 associational/commissural and mossy fiber synapses but not CA1 Schaffer collateral synapses. The depression of synaptic transmission following OGD was prevented by metabotropic glutamate receptor 1 (mGluR1) or $A_{3}$ receptor antagonists, indicating a role for both glutamate and adenosine release. Inhibition of PLC, PKC, or chelation of intracellular $\mathrm{Ca}^{2+}$ also prevented the depression of synaptic transmission. Inclusion of peptides to interrupt the interaction between GluA2 and PICK1 or dynamin and amphiphysin prevented the depression of transmission, suggesting a dynamin and PICK1-dependent internalization of AMPARs after OGD. We also show that a reduction in surface and total AMPAR protein levels after OGD was prevented by mGluR1 or $\mathrm{A}_{3}$ receptor antagonists, indicating that AMPARs are degraded following internalization. Thus, we describe a novel mechanism for the removal of AMPARs in CA3 pyramidal neurons following OGD that has the potential to reduce excitotoxicity and promote neuroprotection.
\end{abstract}

\section{Introduction}

Each region of the hippocampus has a differential resistance to ischemic conditions, with the CA1 being the most susceptible and CA3 and the dentate gyrus most resistant (Kirino et al., 1985; Pulsinelli, 1985; Lipton, 1999). Although mechanisms such as local differences in glutamate receptor expression and sensitivity (Newell et al., 1990; Cronberg et al., 2005; Butler et al., 2010; Sun et al., 2010), synaptic structure (Martone et al., 2000), mitochondrial function (Kass and Lipton, 1986), or $\mathrm{Ca}^{2+}$ influx (Stanika et al., 2010) have been suggested, it remains unclear how, for example, the CA3 region is more resistant to ischemic damage than the neighboring CA1 region.

Ischemia causes a lack of oxygen and glucose, resulting in general metabolic failure that, in turn, leads to a loss of func-

\footnotetext{
Received March 8, 2011; revised June 3, 2011; accepted June 12, 2011.

Author contributions: S.H.D., J.G.H., J.M.H., and J.R.M. designed research; S.H.D., N.J., and H.C. performed research; S.H.D., N.J., H.C., and J.R.M. analyzed data; S.H.D., J.G.H., J.M.H., and J.R.M. wrote the paper.

S.H.D. was supported by a Medical Research Council (MRC) studentship; N.J. was supported by MRC; H.C. was supported by a Marie Curie Fellowship; J.G.H. was supported by Wellcome Trust; J.M.H. was supported by Biotechnology and Biological Sciences Research Council, European Research Council, and MRC; and J.R.M. was supported by MRC, Wellcome Trust, and the European Union Network of European Neuroscience Institutes. We thankS. Kelly and J. Isaac for critical reading of earlier versions of this manuscript and S. Kelly, A. Kenneally, and S. Harris for preliminary experiments.

Correspondence should be addressed to Jack R. Mellor at the above address. E-mail: jack.mellor@bristol.ac.uk. DOI:10.1523/JNEUROSCI.1183-11.2011

Copyright $\odot 2011$ the authors $\quad 0270-6474 / 11 / 3111941-12 \$ 15.00 / 0$
}

tion of $\mathrm{Na}^{+} / \mathrm{K}^{+}$ATP transporters (among many other factors) that maintain the neuronal membrane potential. Failure to maintain the $\mathrm{Na}^{+} / \mathrm{K}^{+}$gradient in the brain prevents glutamate reuptake and causes increased release of glutamate from the cell, resulting in a massive accumulation of extracellular glutamate (Rossi et al., 2000, 2007). The subsequent activation of glutamate receptors coupled with generalized depolarization produces increases in intracellular $\mathrm{Ca}^{2+}$ (Silver and Erecinska, 1990; Tsubokawa et al., 1992; Lipton, 1999), a well documented trigger for cell death (Choi, 1995; Hardingham, 2009). Inhibition of NMDA receptor (NMDAR) function during ischemia can reduce subsequent cell death (Simon et al., 1984; Aarts et al., 2002), and, importantly, activation of $\mathrm{Ca}^{2+}$. permeable AMPA receptors (AMPARs) after ischemia causes delayed cell death (Liu et al., 2004; Noh et al., 2005). $\mathrm{Ca}^{2+}$. permeable AMPARs are not normally present at high levels in CA1 pyramidal neurons, but following ischemia the expression of the GluA2 subunit (that confers $\mathrm{Ca}^{2+}$ impermeability) is reduced leaving predominantly $\mathrm{Ca}^{2+}$-permeable AMPARs (Pellegrini-Giampietro et al., 1992; Tsubokawa et al., 1994; Gorter et al., 1997; Opitz et al., 2000; Noh et al., 2005).

Oxygen/glucose deprivation (OGD) is an established model of ischemia in vitro that can be used to explore potential differences in the response of hippocampal subregions to this insult (Frantseva et al., 1999; Yin et al., 2002; Pugliese et al., 2006; Cimarosti and Henley, 2008; Dixon et al., 2009; Sun et al., 2010). In 
a recent study, we described postsynaptic AMPAR trafficking in CA1 pyramidal neurons following OGD in a process mediated by the PDZ binding protein PICK1 (Dixon et al., 2009). It is not known, however, whether this is a general mechanism common to other cell types within the hippocampus.

Here, we demonstrate that a 15 min OGD protocol produces a substantial and persistent depression of AMPARmediated responses that is specific to CA3 pyramidal neurons of the hippocampus. This depression of synaptic transmission is a postsynaptic event that is independent of NMDAR and AMPAR activity and does not occur in CA1 pyramidal neurons. We find the depression of transmission is mediated by activation of metabotropic glutamate receptor 1 (mGluR1) and adenosine $\mathrm{A}_{3}$ receptors and leads to AMPAR endocytosis and subsequent degradation.

\section{Materials and Methods}

Ethical approval. Animal care and experimental procedures were conducted in accordance with British animal protection legislation and experimental protocols approved by the British National Committee for Ethics in Animal Research.

Slice preparation. Transverse hippocampal slices were prepared from male juvenile (P12-P16) Wistar rats, unless otherwise indicated. Brains were immediately removed following cervical dislocation and immersed in ice-cold aCSF containing the following (in $\mathrm{mm}$ ): $119 \mathrm{NaCl}, 10$ glucose, $26 \mathrm{NaHCO}_{3}, 2.5 \mathrm{KCl}, 1 \mathrm{NaH}_{2} \mathrm{PO}_{4}, 1 \mathrm{CaCl}_{2}$, and $5 \mathrm{MgSO}_{4}$. Individual hippocampi were mounted on agar and $400-\mu \mathrm{m}$-thick slices were cut using a DSK 1000 microslicer (DSK). Following dissection, slices were transferred to aCSF containing the following (in $\mathrm{mm}$ ): $119 \mathrm{NaCl}, 10$ glucose, $26 \mathrm{NaHCO}_{3}, 2.5 \mathrm{KCl}, 1 \mathrm{NaH}_{2} \mathrm{PO}_{4}, 1.3 \mathrm{MgSO}_{4}$, and $2.5 \mathrm{CaCl}_{2}$, maintained at $35^{\circ} \mathrm{C}$ for $30 \mathrm{~min}$, and then stored at room temperature. After dissection, slices were left for a minimum of $1 \mathrm{~h}$ before recordings were made. All solutions were saturated with $95 \% \mathrm{O}_{2}$ and $5 \% \mathrm{CO}_{2}$.

Electrophysiology. Slices were placed in a submerged recording chamber perfused with aCSF (as above) at $35^{\circ} \mathrm{C}$ with the addition of $50 \mu \mathrm{m}$ picrotoxin and $5 \mu \mathrm{M}$ trans-2-carboxy-5,7-dichloro-4-phenylaminocarbonylamino1,2,3,4-tetrahydroquinoline (L-689,560) unless otherwise stated. A high flow rate of $8-10 \mathrm{ml} / \mathrm{min}$ was used to ensure rapid solution exchange times. CA3 pyramidal cells were visualized using infrared-differential interference contrast optics on an Olympus BX-51WI microscope. Patch electrodes with a resistance of $4-5 \mathrm{M} \Omega$ were pulled from borosilicate filamented glass capillaries (Harvard Apparatus) using a vertical puller (PC-10; Narishige). Pipettes were filled with intracellular solution containing the following (in mM): $117 \mathrm{CsMeSO}_{3}, 8 \mathrm{NaCl}, 10$ HEPES, 5 QX-314, $4 \mathrm{Mg}$-ATP, $0.3 \mathrm{Na}-\mathrm{GTP}$, 0.2 EGTA, 0.1 bestatin, and 0.1 leupeptin, set to $\mathrm{pH} 7.4,280-285 \mathrm{mOsm}$.

Recordings from CA3 pyramidal neurons were made with a Axopatch 200B amplifier (Molecular Devices), filtered at $5 \mathrm{kHz}$, and digitized at 10 $\mathrm{kHz}$ using a data acquisition board and Signal acquisition software (CED). Cells were voltage clamped at -70 (without junction potential correction). Series resistance was monitored throughout the experiments, and cells that showed $>20 \%$ change were discarded from subsequent analysis. Recordings were also rejected from analysis if the series resistance was $>30 \mathrm{M} \Omega$. Extracellular field potential recordings were made from hippocampal slices bathed in aCSF using a patch pipette filled with aCSF. The peak amplitude of evoked synaptic responses was measured to calculate response amplitude. Synaptic responses were evoked with $100 \mu$ s square voltage steps applied at $0.05 \mathrm{~Hz}$ through a bipolar stimulating electrode (FHC) located in stratum radiatum (for associational/commissural or Schaffer collateral stimulation) or the granule cell layer (for mossy fiber stimulation). The recording electrode was placed in stratum radiatum of CA1 (for Schaffer collateral recording) or CA3 (for associational/commissural recording) or in stratum lucidum in CA3 (for mossy fiber recording). Purity of mossy fiber responses was checked by application of the group II mGluR agonist DCG-IV $\left[\left(2 S, 2^{\prime} R, 3^{\prime} R\right)-2-\right.$ $\left(2^{\prime}, 3^{\prime}\right.$-dicarboxycyclopropyl)glycine] $(2 \mu \mathrm{M})$ (Kamiya et al., 1996) at the end of each experiment and if there was $<80 \%$ depression the experiment was discarded from subsequent analysis ( 0 of 4 experiments).
Focal application of aCSF containing $10 \mathrm{~mm}$ glutamate was performed by pressure ejection ( $150 \mathrm{~ms}, 30-90 \mathrm{kPa})$ under the control of a spritzer (made in house) through a glass electrode with a resistance of 3-4 M $\Omega$ placed in stratum radiatum close to the cell body layer.

OGD was induced by perfusing slices with aCSF saturated with $95 \%$ $\mathrm{N}_{2} / 5 \% \mathrm{CO}_{2}$ and containing $10 \mathrm{~mm}$ sucrose instead of $10 \mathrm{~mm}$ glucose.

L-689,560, kynurenic acid, $N$-(2-methoxyphenyl)- $N^{\prime}$-[2-(3-pyrindinyl)4-quinazolinyl]-urea (VUF5574), 6-amino- $N$-cyclohexyl- $N, 3$-dimethylthiazolo[3,2-a]benzimidazole-2-carboxamide hydrochloride (YM298198), (2S)-2-amino-2-[(1S,2S)-2-carboxycycloprop-1-yl]-3-(xanth-9-yl)propanoic acid (LY341495), MPEP, EVKI, SVKI, EVKE, BAPTA, O-(octahydro-4, 7-methano-1 $H$-inden-5-yl)carbonopotassium dithioate (D609), P4, (RS)3,5-dihydroxyphenylglycine (DHPG), and 1-[2-chloro-6-[[(3-iodophenyl) methyl] amino]-9H-purin-9-yl]-1-deoxy- $N$-methyl- $\beta$-D-ribofuranuronamide (2-Cl-IB-MECA) were purchased from Tocris. 3-Ethyl-5-benzyl-2-methyl-4phenylethynyl-6-phenyl-1,4-(土)-dihydropyridine-3,5-dicarboxylate (MRS1191), picrotoxin, and PKC19-36 were purchased from Sigma-Aldrich.

Slice biotinylation. Acute hippocampal slices $(400 \mu \mathrm{m})$ were washed once with ice-cold aCSF (5 min) and then incubated with Sulfo-NHSSS-Biotin (Pierce; $0.5 \mathrm{mg} / \mathrm{ml}$ in aCSF) for $30 \mathrm{~min}$ on ice. Excess biotin was removed by two brief washes with $50 \mathrm{mM} \mathrm{NH}_{4} \mathrm{Cl}$ (in aCSF) and two aCSF washes. The CA1 and CA3 regions were separated and then lysed in $300 \mu \mathrm{l}$ of ice-cold lysis buffer ( $150 \mathrm{~mm} \mathrm{NaCl}, 20 \mathrm{~mm}$ HEPES, $1 \%$ Triton $\mathrm{X}-100,0.1 \%$ SDS, 2 mM EDTA, pH 7.4) containing protease inhibitors (protease inhibitor mixture with EDTA; Roche). Samples were then sonicated and placed on a head-over-head shaker for $2 \mathrm{~h}$. Samples were then centrifuged at 13,000 rpm for $10 \mathrm{~min}$ and the pellets were discarded. The protein concentration of the resulting supernatant was determined using a BCA kit (Pierce).

Streptavidin pull down. Lysed biotinylated samples were added to the streptavidin beads and mixed on a head-over-head shaker for $2 \mathrm{~h}$. Beads were subsequently washed three times with lysis buffer and biotinylated proteins were eluted from the beads using $2 \times$ SDS-PAGE loading buffer (containing $\beta$-mercaptoethanol) and heated to $90^{\circ} \mathrm{C}$ for $5 \mathrm{~min}$.

Western blots and densitometry. For Western blot analysis, the CA1 and CA3 regions were isolated with a scalpel from eight hippocampal slices per animal, immersed in lysis buffer containing the following: $50 \mathrm{~mm}$ Tris- $\mathrm{HCl}, \mathrm{pH}$ 7.4, $150 \mathrm{~mm} \mathrm{NaCl}, 1 \mathrm{~mm}$ EDTA, 0.1\% SDS, $1 \%$ Triton $\mathrm{X}-100$, and mammalian protease inhibitor mixture, and homogenized on ice, and the protein concentration was determined. Samples were heated for $5 \mathrm{~min}$ at $95^{\circ} \mathrm{C}$ with $5 \% \beta$-mercaptoethanol and subjected to SDS-PAGE. The primary antibodies used in Figure $8 a$ were as follows: rabbit polyclonal anti-GluA1 antibody (1:2000; Millipore), mouse polyclonal anti-GluA2/3 antibody (1:1500; Millipore Bioscience Research Reagents), and mouse monoclonal anti- $\beta$-actin (1:50,000; Sigma-Aldrich). Because of the lack of availability of antibodies, the primary antibodies used in Figures 7 and $8 b$ were as follows: mouse polyclonal anti-GluA1 and GluA2 antibodies (both at 1:2000; Millipore) and mouse polyclonal anti- $\beta$-tubulin antibody (1:50,000; Sigma-Aldrich). The membrane was incubated with horseradish peroxidase-conjugated secondary antibodies (1:10,000; Sigma-Aldrich). In CA1 and CA3 sections, OGD groups were compared with their respective controls, which were designated as $100 \%$, on the same Western blot to avoid any differences in signal intensity due to exposure times. Similarly, in the experiments using different drugs, OGD groups treated with each specific drug were compared with nonOGD-exposed groups treated with the respective drugs. All the blots were also probed with anti- $\beta$-actin or anti- $\beta$-tubulin antibodies as an internal control. The band intensity was quantified by densitometry using NIH ImageJ, and the GluA1/2 values were normalized to $\beta$-actin/ $\beta$-tubulin.

Data analysis. Within an electrophysiological data set, statistical comparison was made between $10 \mathrm{~min}$ baseline recording and the recording made 20-30 min following the end of OGD or drug application, using a Student's two-tailed paired $t$ test. For experiments on the effect of intracellular infusion, within-data set comparison was made between the first minute recording and that made 15-20 min after membrane rupture using a Student's two-tailed paired $t$ test. Reported tests are within data set unless otherwise stated. Across data sets, statistical comparison was made comparing the normalized data 20-30 min 
a

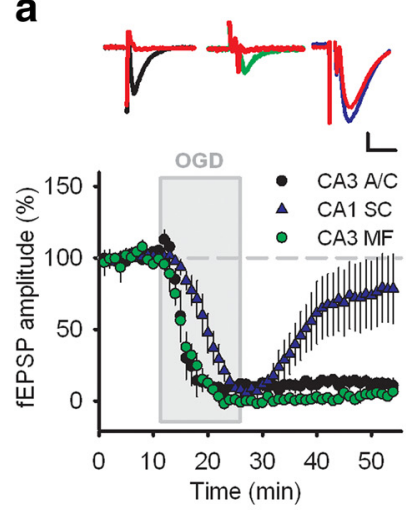

C

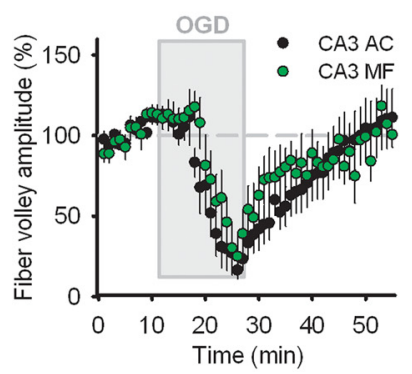

e

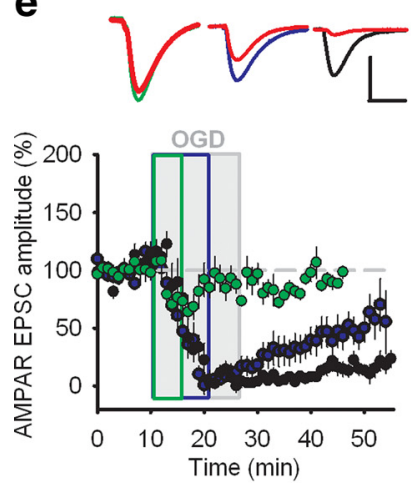

b
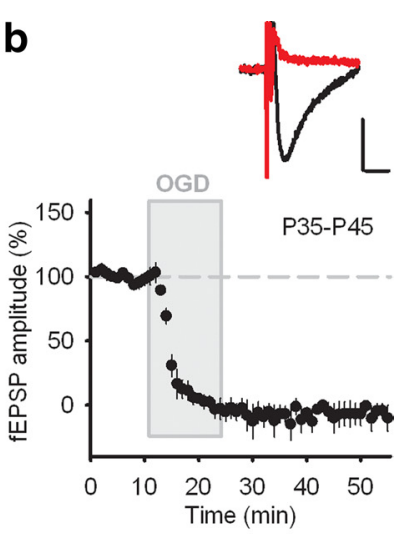

d

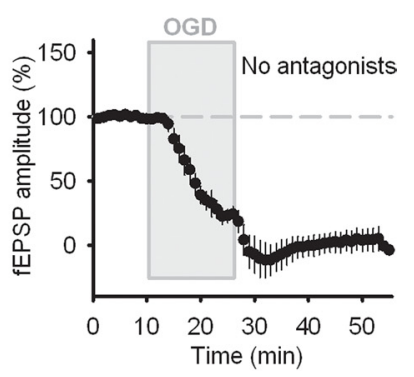

f
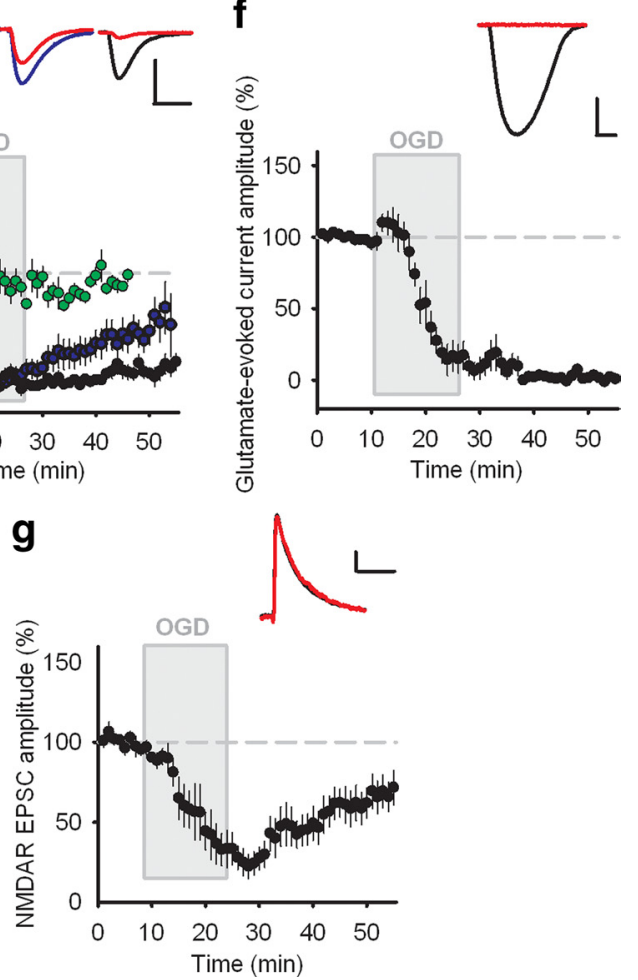

Figure 1. OGD induces depression of AMPAR-mediated responses in CA3 neurons. $\boldsymbol{a}, \mathrm{A}$ substantial depression of fEPSP amplitude was observed at both $A C$ and MF synapses in CA3 but not at $S C$ synapses in CA1 following OGD. $\boldsymbol{b}$, Fifteen minute OGD resulted in a substantial depression of fEPSPs at AC synapses in CA3 in slices from P35-P45 rats. C, No long-term reduction in fiber volley amplitude was observed at $\mathrm{MF}$ or $\mathrm{AC}$ synapses following $O G D$. $\boldsymbol{d}$, Fifteen minute $O G D$ resulted in a substantial depression of fEPSPs at $A C$ synapses in CA3 in the absence of NMDAR antagonists. $\boldsymbol{e}$, Increasing the duration of OGD $(5,10$, and 15 min indicated by boxes) resulted in an increased reduction in AMPAR EPSC amplitude. $f$, Fifteen minute $0 G D$ resulted in a substantial depression of AMPAR-mediated responses in CA3 pyramidal neurons evoked by exogenous glutamate $(10 \mathrm{mM})$ application following the end of OGD or drug application using a Student's unpaired two-tailed $t$ test.

Within Western blot data sets, statistical comparisons were made between normalized control and OGD conditions using one-sample twotailed $t$ tests. Subsequent comparisons between OGD, OGD plus MRS1191, and OGD plus YM298198 were made using one-way ANOVA with Bonferroni's post hoc correction. All data are expressed as mean \pm SEM. Values of $p<0.05$ were considered statistically significant.

\section{Results}

OGD induces a depression of AMPA receptor-mediated responses in CA3 neurons

OGD or in vivo ischemia causes a decrease in GluA2 containing and an increase in GluA1 homomeric AMPARs at Schaffer collateral synapses in the CA1 region of the hippocampus (Pellegrini-Giampietro et al., 1992; Tsubokawa et al., 1994; Gorter et al., 1997; Opitz et al., 2000; Noh et al., 2005; Dixon et al., 2009). We therefore tested whether this process also occurs at other hippocampal synapses.

We initially used extracellular field potential recording to assess the effect of 15 min OGD on synaptic transmission recorded (in the presence of NMDAR antagonist L-689,560) at three separate synapses in hippocampal slices: the Schaffer collateral (SC) synapse in CA1, the associational/commissural (AC) synapse in $\mathrm{CA} 3$, and the mossy fiber (MF) synapse in CA3. We observed two distinct effects of OGD between synapses of the CA3 and CA1 regions. After obtaining a stable $10 \mathrm{~min}$ baseline, a $15 \mathrm{~min}$ period of OGD was applied, followed by a $30 \mathrm{~min}$ recovery period in which the slice was bathed in oxygen and glucose containing aCSF. OGD resulted in a transient depression of field EPSPs (fEP$\mathrm{SPs}$ ) recorded at $\mathrm{MF}, \mathrm{AC}$, and SC synapses. However, OGD caused a persistent substantial depression of synaptic transmission at CA3 MF and AC synapses but not at CA1 SC synapses (Fig. 1a) (MF, $2 \pm 2 \%, n=4, p<0.001$; AC, $12 \pm 4 \%, n=5, p<0.05$; $\mathrm{SC}, 78 \pm 12 \%, n=4, p>0.05)$. As juvenile rats are less susceptible to ischemic damage than adult rats (Popa-Wagner et al., 2007), we performed the same experiment on hippocampal slices obtained from P35-P45 rats. The same substantial depression of synaptic transmission at AC synapses in the $\mathrm{CA} 3$ region was observed following OGD (Fig. $1 b)(6 \pm 8 \% ; n=5 ; p<0.01)$. Extracellularly recorded fiber volleys revealed a transient depression in fiber volley amplitude during OGD that recovered to baseline within $30 \mathrm{~min}$ at both $\mathrm{AC}$ and MF synapses (Fig. 1c) (MF, $98 \pm 10 \%, n=9, p>0.05 ; \mathrm{AC}, 103 \pm 18 \%, n=7, p>0.05)$. These data indicate the transient depression during OGD, but not the sustained depression of synaptic transmission following OGD, is due to an inhibition of presynaptic action potentials. We also applied $15 \mathrm{~min}$ of OGD to hippocampal slices in the absence of any AMPAR, NMDAR, or $\mathrm{GABA}_{\mathrm{A}} \mathrm{R}$ antagonists. The same depression in fEPSP amplitude was observed (Fig. 1d) $(2 \pm 7 \%$; $n=7 ; p<0.001)$, indicating that the depression of synaptic transmission in CA3 occurred in the presence or absence of NMDAR antagonists.

We observed the same depression of synaptic transmission when making whole-cell voltage-clamp recordings from CA3 pyramidal neurons and stimulating AC fibers in stratum radiatum. In the presence of $\mathrm{NMDAR}$ and $\mathrm{GABA}_{\mathrm{A}}$ receptor antagonists

$\leftarrow$

to stratum radiatum. $\boldsymbol{g}$, OGD did not cause a long-term depression of NMDAR EPSCS at AC synapses in CA3. The gray box indicates 15 min period of OGD. Example traces illustrate responses before (black, green, or blue) and 20-30 min following OGD (red). Calibration: $\boldsymbol{a}, \boldsymbol{b}, \boldsymbol{d}$, $0.05 \mathrm{mV} ; \boldsymbol{e}-\boldsymbol{g}, 50 \mathrm{pA} ; \boldsymbol{a}, \boldsymbol{b}, \boldsymbol{d}, \boldsymbol{e}, 10 \mathrm{~ms} ; \boldsymbol{f}, \boldsymbol{g}, 200 \mathrm{~ms}$. Error bars indicate SEM. 
(L-689,560 and picrotoxin, respectively), AMPAR-mediated EPSCs were substantially depressed following 15 min OGD (Fig. 1e) (15 min, $15 \pm 6 \% ; n=7 ; p<0.001)$. Shorter durations of OGD produced smaller reductions in AMPAR EPSC amplitude (Fig. 1e) (10 $\mathrm{min}, 43 \pm 12 \%, n=11, p<0.05 ; 5 \mathrm{~min}, 95 \pm 6 \%$, $n=7, p>0.05)$. During in vivo ischemia or OGD, a delayed, but rapid-onset, depolarization has been observed, which recovers with reperfusion or reapplication of glucose and oxygen (Hansen, 1985; Rossi et al., 2000; Joshi and Andrew, 2001). Toward the end of OGD exposure, we consistently observed a rapid increase in holding current that corresponds to this depolarization (average for 15 min OGD, $758 \pm 138 \mathrm{pA} ; n=7$ ).

The depression of synaptic transmission could be due to impaired presynaptic glutamate release or a reduction in postsynaptic responsiveness. To distinguish between these possibilities, we bypassed the presynaptic release of neurotransmitter using application of exogenous glutamate $(10 \mathrm{~mm})$ by pressure ejection from a glass pipette placed in stratum radiatum, while making whole-cell voltage-clamp recordings from CA3 pyramidal neurons. Glutamate-evoked currents in the presence of the NMDAR antagonist L-689,560 $(5 \mu \mathrm{M})$ and the $\mathrm{GABA}_{\mathrm{A}}$ receptor antagonist picrotoxin $(50 \mu \mathrm{M})$ displayed a persistent reduction following OGD (Fig. $1 f)(2 \pm 1 \% ; n=7 ; p<0.001)$. The same result was observed when the experiment was performed in the absence of picrotoxin $(3 \pm 1 \% ; n=8 ; p<0.001)$ (data not shown).

We also tested whether the depression of synaptic transmission on CA3 pyramidal neurons was specific for AMPAR-mediated transmission. NMDAR EPSCs were evoked by stimulation of the AC fibers, while recording from CA3 pyramidal neurons voltage clamped at $+40 \mathrm{mV}$ in the presence of NBQX $(20 \mu \mathrm{M})$ and picrotoxin $(50 \mu \mathrm{M})$ to block AMPAR and $\mathrm{GABA}_{\mathrm{A}} \mathrm{R}$, respectively. After a transient decrease in the amplitude of NMDAR EPSCs during OGD, there was a substantial recovery following OGD, demonstrating that the long-term depression of synaptic transmission is specific for AMPAR-mediated transmission (Fig. $1 g)(74 \pm 7 \% ; n=11 ; p>$ $0.05)$. These data suggest the depression of synaptic transmission in CA3 pyramidal neurons following OGD is a postsynaptic event resulting from a removal or inactivation of AMPARs at both synaptic and extrasynaptic sites.

\section{OGD-induced depression of synaptic transmission requires mGluR1 but not AMPAR or NMDAR activation}

Metabolic failure results in prolonged excess glutamate release during OGD, which leads to glutamate receptor activation (Rossi et al., 2000). We therefore tested a range of antagonists to determine which, if any, glutamate receptors mediated the depression of synaptic transmission at the AC synapse in CA3 after OGD. Our recordings in Figure 1, $a, b, e$, and $f$, were all performed in the presence of an NMDAR antagonist, indicating the depression of synaptic transmission after OGD is not NMDAR dependent. To test whether AMPA or kainate receptor activation is required for the depression of synaptic transmission following OGD, we used the low-affinity AMPA/kainate receptor antagonist kynurenic acid. A 15 min application of $2 \mathrm{~mm}$ kynurenic acid substantially reduced AMPAR EPSCs at AC synapses recorded in the presence of NMDAR and $\mathrm{GABA}_{\mathrm{A}}$ receptor antagonists L-689,560 and picrotoxin (Fig. 2a) (20 $\pm 4 \% ; n=5 ; p<0.05)$, which then fully recovered within 20 min of wash out $(93 \pm 12 \% ; n=5 ; p>0.05$ compared with baseline). The $2 \mathrm{~mm}$ kynurenic acid was then applied for the 15 min period of OGD to inhibit AMPAR activity. Inhibition of AMPARs during OGD failed to prevent the depression of synaptic transmission following OGD (Fig. 2b) (12 $\pm 3 \%$; $n=8 ; p<0.001)$, suggesting that direct agonist activation of
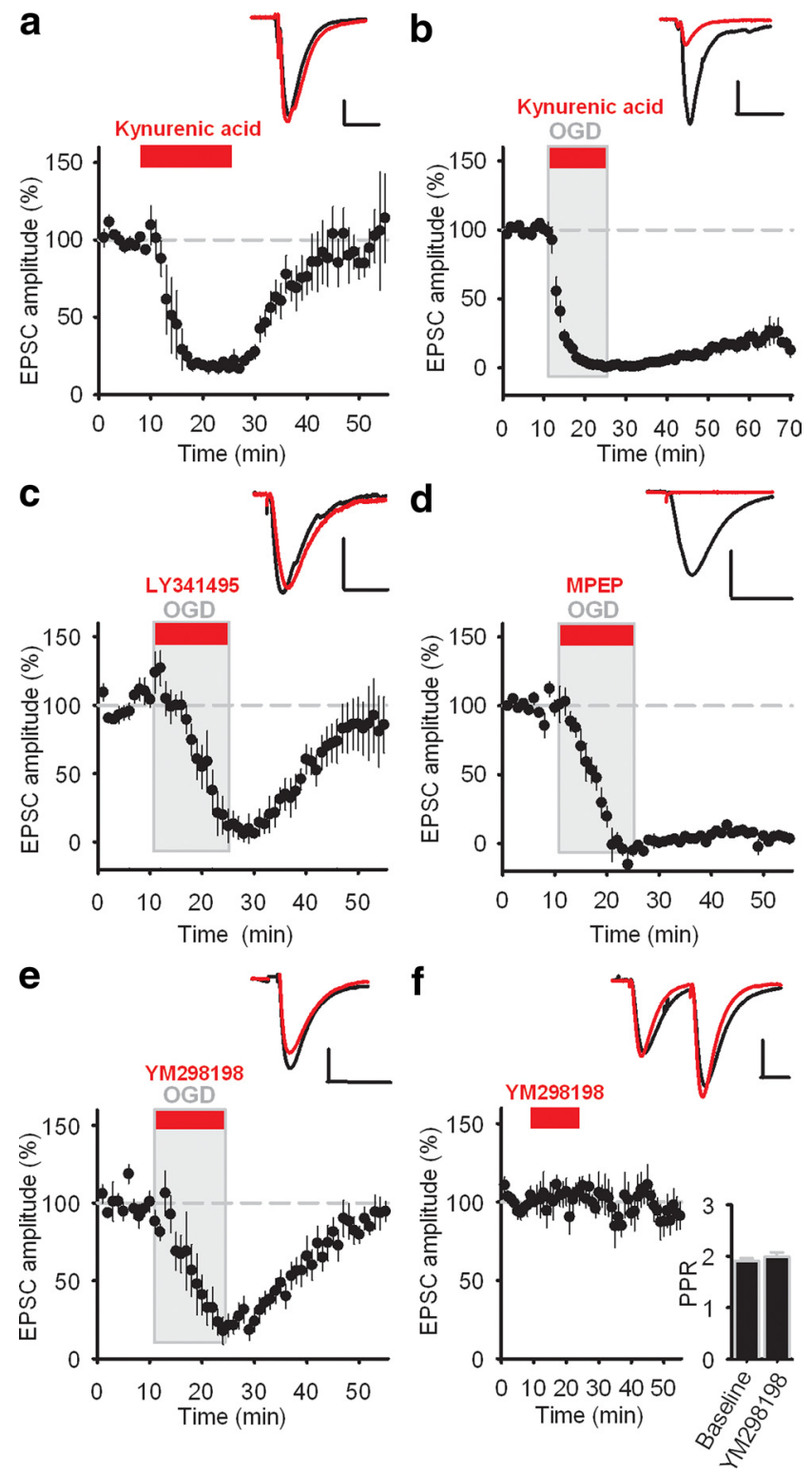

Figure 2. Depression of AMPAR EPSCs following OGD is dependent on mGluR1 but not AMPAR or NMDAR activation. $\boldsymbol{a}$, Application of $2 \mathrm{~mm}$ kynurenic acid resulted in a transient reduction in AMPAREPSC amplitude. $\boldsymbol{b}$, Application of 2 mm kynurenic acid during OGD failed to prevent the depression of AMPAR EPSCS. c, Application of $100 \mu \mathrm{m}$ LY341495 during 0GD prevented the depression of AMPAR EPSCs. $\boldsymbol{d}$, Application of $30 \mu \mathrm{M}$ MPEP failed to prevent the depression of AMPAR EPSCs. e, Application of $50 \mathrm{~nm}$ YM298198 prevented the depression of AMPAR EPSCs. f, Application of $50 \mathrm{~nm}$ YM298198 had no effect on AMPAR EPSC amplitude or PPR. The gray boxes indicate $15 \mathrm{~min}$ period of $0 \mathrm{GD}$. Example traces illustrate responses before (black) and 20-30 min following 0GD or antagonist application (red). Calibration: 50 pA, 20 ms. Error bars indicate SEM.

AMPARs during OGD is not the primary mechanism underlying the decrease in functional AMPARs.

We next investigated whether mGluRs could mediate the depression of synaptic transmission. There are eight known mGluR subtypes that are classified into three groups. To test a role for mGluRs in the depression of AMPAR EPSCs following OGD, the mGluR antagonist LY341495 (100 $\mu \mathrm{M})$ was applied during OGD. At this concentration, all mGluR subtypes are blocked by this antagonist. LY341495 prevented the long-term depression of synaptic transmission following OGD, demonstrating a role for mGluRs (Fig. 2c) (85 $\pm 18 \% ; n=6 ; p>0.05)$. Group I mGluRs 
consist of mGluR1 and mGluR5, which are predominantly found postsynaptically within the hippocampus where they mediate a form of LTD and are thus likely candidates to mediate the depression of synaptic transmission following OGD (Moult et al., 2006; Lüscher and Huber, 2010). Application of the mGluR5 antagonist MPEP $(30 \mu \mathrm{M})$ failed to prevent the depression of AMPAR EPSCs following OGD (Fig. $2 d)(5 \pm 2 \% ; n=6$; $p<0.001)$, suggesting that mGluR5 activation is not involved. However, application of the mGluR1 antagonist YM298198 (50 nM) during OGD did prevent the depression of AMPAR EPSCs following OGD (Fig. $2 e$ ) (91 $\pm 4 \% ; n=7 ; p>0.05)$. Importantly, application of $50 \mathrm{~nm}$ YM298198 alone did not result in any change in EPSC amplitude or paired-pulse ratio (PPR) (Fig. 2f) (92 $\pm 7 \%$; PPR, $108 \pm 5 \% ; n=7 ; p>0.05$ for both), suggesting that inhibition of mGluR1 does not modulate AMPAR-mediated responses or change presynaptic probability of release under control conditions.

\section{OGD-induced depression of synaptic transmission requires} adenosine $\mathrm{A}_{3}$ receptor activation

Under stress conditions, such as those evoked during ischemia and OGD, high levels of adenosine are released within the hippocampus (Latini et al., 1999; Latini and Pedata, 2001). Of the four adenosine receptor subtypes, $A_{1}, A_{2 a}, A_{2 b}$, and $A_{3}, A_{1}$ and $A_{2 a}$ are predominantly located presynaptically and affect release probability at excitatory synapses and $\mathrm{A}_{2 \mathrm{~b}}$ is absent from the hippocampus (Cunha et al., 1994; Swanson et al., 1995; Dixon et al., 1996; Dunwiddie and Masino, 2001; Rebola et al., 2005). A A $_{3}$ receptors are present in the hippocampus, but their presynaptic or postsynaptic location remains unclear. Similar to mGluR1, $A_{3}$ receptors are G-protein-coupled receptors, typically linked to $\mathrm{G}_{\mathrm{q}}$ and $\mathrm{G}_{\mathrm{i} / \mathrm{o}}$ affecting phospholipase $\mathrm{C}$ (PLC) and adenyl cyclase activity. Interestingly, $\mathrm{A}_{3}$ receptor activation appears to be neuroprotective during ischemia, although a precise role is unclear (von Lubitz et al., 1999; Pugliese et al., 2006).

Consistent with this, application of the $\mathrm{A}_{3}$ antagonist VUF5574 (100 nM) during OGD prevented the depression of AMPAR EPSCs at AC synapses following OGD (Fig. 3a) (100 \pm $21 \% ; n=6 ; p>0.05$ ). To confirm the requirement for $\mathrm{A}_{3}$ receptor activation, another $\mathrm{A}_{3}$ antagonist MRS1191 $(1 \mu \mathrm{M})$ was applied during OGD that also prevented the depression of AMPAR EPSCs (Fig. 3b) ( $83 \pm 7 \% ; n=7 ; p>0.05)$. Application of either antagonist alone without OGD did not change the AMPAR EPSC amplitude or PPR (Fig. 3c,d) (VUF, $93 \pm 10 \%$; PPR, $114 \pm 8 \%$; $n=6 ; p>0.05$ for both; MRS, $87 \pm 9 \%$; PPR, $99 \pm 10 \% ; n=7$; $p>0.05$ for both). These experiments indicate that $A_{3}$ receptor activation during OGD is required for the depression of AMPAR EPSCs following OGD.

Activation of mGluR1 and $A_{3}$ receptors is not sufficient for complete depression of synaptic transmission following OGD The results so far demonstrate that mGluR1 and $\mathrm{A}_{3}$ receptor activation during OGD is necessary for the long-term depression of AMPAR EPSCs. Therefore, we next determined whether activation of $\mathrm{mGluR} 1$ and $\mathrm{A}_{3}$ receptors alone is also sufficient to elicit the depression of AMPAR EPSCs by application of the group I mGluR agonist DHPG and the $\mathrm{A}_{3}$ agonist 2-Cl-IB-MECA. A 15 min application of DHPG $(50 \mu \mathrm{M})$ resulted in a depression of AMPAR EPSCs without any effect on PPR (Fig. $4 a)(56 \pm 11 \%$; $n=6$; $p<0.05$; PPR, $124 \pm 15 \%$; $p>0.05)$. Similarly, application of 2-Cl-IB-MECA $(1 \mu \mathrm{M})$ also caused a depression of AMPAR EPSCs without any effect on PPR (Fig. $4 b)(61 \pm 8 \% ; n=7$; $p<0.05$; PPR, $122 \pm 8 \%$; $p>0.05)$. However, submaximal
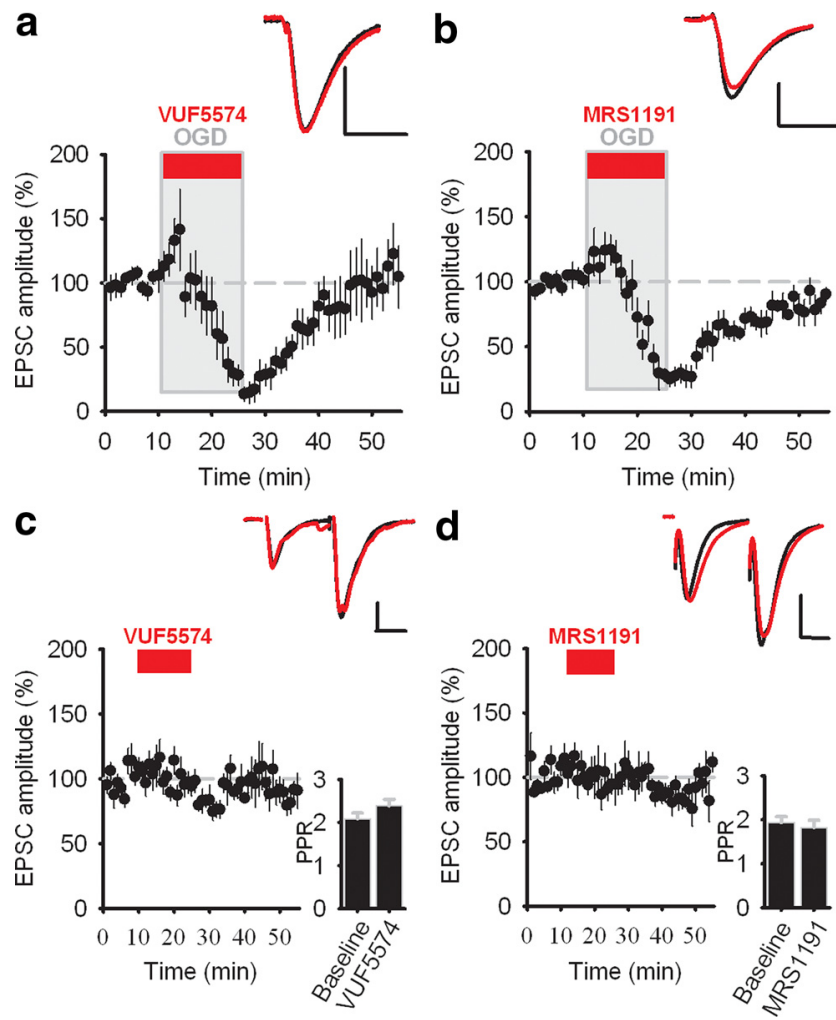

Figure 3. $A_{3}$ receptor activation is required for the depression of AMPAR EPSCs following OGD. $\boldsymbol{a}$, Application of the $A_{3}$ receptor antagonist VUF5574 (100 nM) during OGD prevented the depression of AMPAR EPSCs. $\boldsymbol{b}$, Application of the $\mathrm{A}_{3}$ receptor antagonist MRS1191 (1 $\left.\mu \mathrm{M}\right)$ during OGD prevented the depression of AMPAR EPSCs. Application of VUF5574 (c) or MRS1191 (d) had no effect on AMPAR EPSC amplitude or PPR. The gray boxes indicate $15 \mathrm{~min}$ period of OGD. Example traces illustrate responses before (black) and 20-30 min following OGD or antagonist application (red). Calibration: 50 pA, 20 ms. Error bars indicate SEM.

concentrations of DHPG (50 nM) and 2-Cl-IB-MECA (500 nM) produced no depression of AMPAR EPSCs (Fig. 4c,d) (107 \pm $11 \%, n=6, p>0.05 ; 111 \pm 22 \%, n=6, p>0.05)$, but when both agonists were applied conjointly at the same submaximal concentrations a depression of AMPAR EPSCs was observed (Fig. 4e) (42 $\pm 3 \% ; n=6 ; p<0.01)$. This indicates that mGluR1 and $\mathrm{A}_{3}$ receptors can act in a complementary fashion to depress synaptic transmission at AC synapses in CA3. We next tested whether conjoint application of supramaximal concentrations of DHPG and 2-Cl-IB-MECA could reproduce the substantial depression of AMPAR EPSCs seen after OGD. DHPG (50 $\mu \mathrm{M})$ and 2-Cl-IBMECA $(1 \mu \mathrm{M})$ reduced AMPAR EPSC amplitude only to the same level as submaximal concentrations (Fig. $4 f)(43 \pm 10 \%$; $n=9 ; p<0.01 ; \mathrm{PPR}=117 \pm 10 \% ; p>0.05)$, indicating that simultaneous activation of mGluR1 and $A_{3}$ receptors is not sufficient for the substantial depression of synaptic transmission following OGD.

OGD causes release of glutamate and adenosine and also depolarization of neurons. Therefore, we tested whether the combination of all three events could recapitulate the effects of OGD on synaptic transmission. The DHPG $(50 \mu \mathrm{M})$ - and 2-Cl-IBMECA $(1 \mu \mathrm{M})$-induced depression was enhanced by depolarizing the postsynaptic cell to $0 \mathrm{mV}$ during application of the mGluR1 and $\mathrm{A}_{3}$ receptor agonists (Fig. $\left.4 g\right)(26 \pm 6 \% ; n=6 ; p<0.01)$. The 15 min depolarization was delayed $5 \mathrm{~min}$ compared with agonist application to ensure agonist presence during depolarization. The level of depression induced by DHPG, 2-Cl-IB-MECA, and postsynaptic depolarization was indistinguishable to that in- 
a
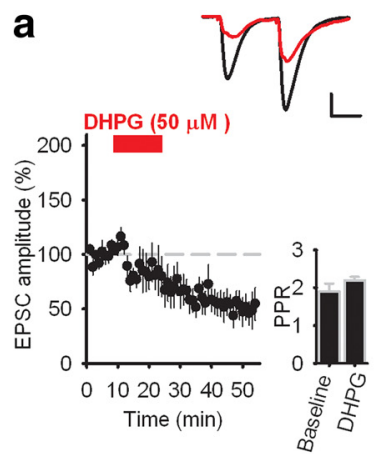

C

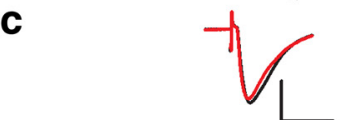

DHPG $(50 \mathrm{nM})$

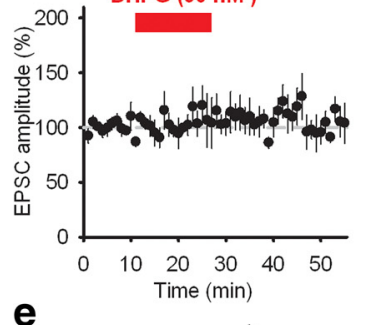

e

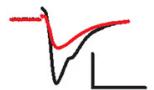

DHPG (50 nM ) + MECA $(500 n M)$

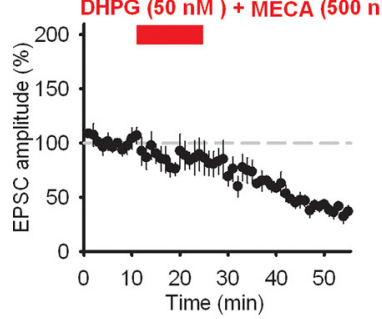

g
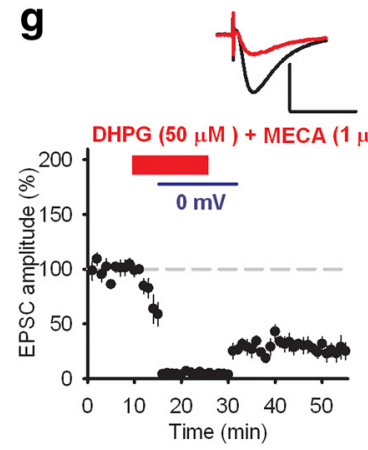

b

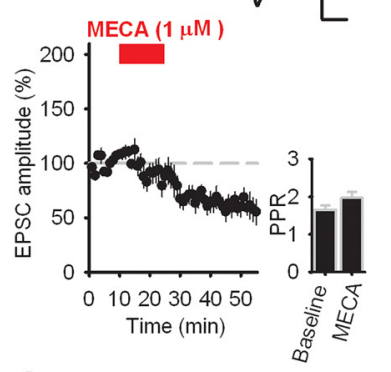

d
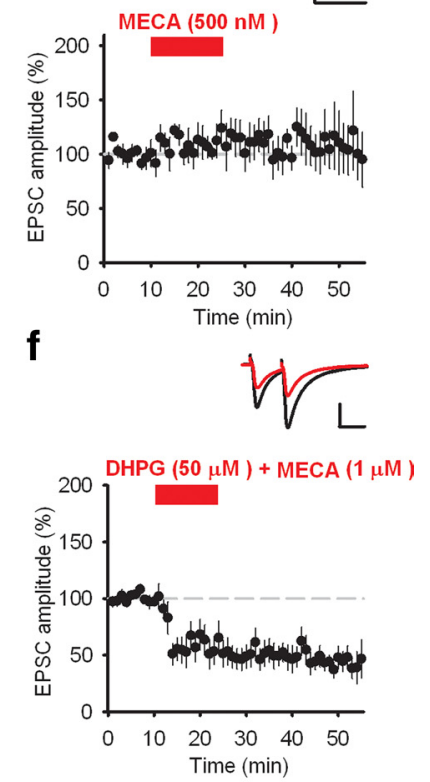

h
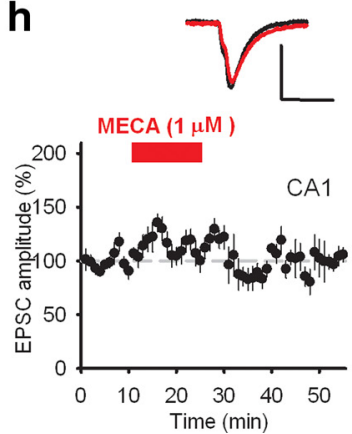

Figure 4. Group I mGluR or $\mathrm{A}_{3}$ receptor activation causes depression of AMPAREPSCs. $\boldsymbol{a}$, Application of the group I mGluR agonist DHPG $(50 \mu \mathrm{M})$ produced a long-term depression of AMPAR EPSCs but no change in PPR. $\boldsymbol{b}$, Application of the $\mathrm{A}_{3}$ receptor agonist 2-Cl-IBMECA $(1 \mu \mathrm{M})$ produced a long-term depression of AMPAR EPSCs but no change in PPR. $c$, Application of a submaximal concentration of DHPG $(50 \mathrm{~nm})$ produced no change in AMPAR EPSCs. d, Application of a submaximal concentration of 2-CI-IB-MECA (500 nM) produced no change in AMPAR EPSCs. $\boldsymbol{e}$, Application of 2-CI-IB-MECA (500 nM) and DHPG $(50 \mathrm{~nm})$ produced a long-term depression of AMPAR EPSCs. $f$, Application of 2-CI-IB-MECA $(1 \mu \mathrm{M})$ and DHPG $(50 \mu \mathrm{M})$ produced a long-term depression of AMPAR EPSCs. $\boldsymbol{g}$, Application of 2-CI-IB-MECA $(1 \mu \mathrm{m})$ and DHPG $(50 \mu \mathrm{m})$ together with depolarization of the postsynaptic membrane to $0 \mathrm{mV}$ produced a long-term depression of AMPAR EPSCs. Fifteen minute depolarization was delayed 5 min compared with agonist application. $\boldsymbol{h}$, Application of 2-CI-IB-MECA (1 $\mu \mathrm{M})$ produced no change in AMPAR EPSCs recorded from Schaffer collateral stimulation in CA1. Example traces illustrate responses before (black) and 20 $-30 \mathrm{~min}$ following agonist application (red). Calibration: 100 pA, 20 ms. Error bars indicate SEM.

duced by OGD ( $p>0.05)$, indicating that the combination of all three is sufficient to replicate the depression of synaptic transmission by OGD.

Interestingly, although a supramaximal dose of the $\mathrm{A}_{3}$ agonist 2-Cl-IB-MECA $(1 \mu \mathrm{M})$ produced a depression of synaptic transmission at AC synapses in CA3, there was no effect on Schaffer collateral synapses in CA1 (Fig. 4h) $(90 \pm 4 \% ; n=7 ; p>0.05)$. This suggests that $A_{3}$ receptors may be absent from CA1 cells and thus provides a possible explanation for the difference in response to OGD between hippocampal subregions.

OGD-induced depression of synaptic transmission requires intracellular calcium and is mediated by PKC and PLC activity

In vivo ischemia or OGD evoke rises in intracellular $\mathrm{Ca}^{2+}$ concentration (Silver and Erecinska, 1990; Lipton, 1999). To test whether this is important for the depression of AMPAR EPSCs following OGD, two experimental approaches were used. The first used removal of $\mathrm{Ca}^{2+}$ from aCSF for the period during and $15 \mathrm{~min}$ after OGD. This prevented the depression of AMPAR EPSCs following OGD (Fig. $5 a)(70 \pm 6 \% ; n=7 ; p>0.05 ; p<$ 0.05 compared with OGD in the presence of $\mathrm{Ca}^{2+}$ ). The second experiment used the $\mathrm{Ca}^{2+}$ chelator BAPTA included in the patch pipette. Inclusion of $50 \mathrm{~mm}$ but not $10 \mathrm{mM} B A P T A$ also prevented the depression of AMPAR EPSCs at AC synapses following OGD (Fig. $5 b)(50 \mathrm{~mm}, 83 \pm 10 \%, n=9, p>0.05 ; 10 \mathrm{~mm}, 3 \pm 1 \%, n=$ $7, p<0.001)$. The high concentration of BAPTA required to buffer a rise in intracellular $\mathrm{Ca}^{2+}$ suggests, as previously reported, that ischemia or OGD causes a substantial increase in intracellular $\mathrm{Ca}^{2+}$ that is required for the depression of synaptic transmission following OGD.

Both mGluR1 and $A_{3}$ receptors are coupled to $G_{q}$-proteins that activate PLC, which subsequently results in two main pathways of intracellular signaling. PLC, via inositol trisphosphate $\left(\mathrm{IP}_{3}\right)$ activation, leads to the release of $\mathrm{Ca}^{2+}$ from intracellular stores (Abbracchio et al., 1995; Palmer et al., 1995) and, via the cleavage of phosphatidylinositol 4,5-bisphosphate $\left(\mathrm{PIP}_{2}\right)$, produces diacylglycerol $(\mathrm{DAG})$, which in turn activates protein kinase C (PKC) (Abbracchio et al., 1995). To determine whether these downstream signaling pathways mediate the depression of synaptic transmission following OGD, both PKC and PLC inhibitors were used. Inclusion of the PLC inhibitor D609 $(30 \mu \mathrm{M})$ in the patch pipette prevented the depression of AMPAR EPSCs at AC synapses following OGD (Fig. $5 c)(80 \pm 10 \% ; n=7 ; p>0.05)$. Similarly, inclusion of the PKC inhibitory peptide PKC19-36 (4.8 $\mu \mathrm{M})$ in the patch pipette also prevented the depression of AMPAR EPSCs (Fig. 5e) $(84 \pm 10 \% ; n=7 ; p>0.05)$. Recordings made immediately following membrane rupture demonstrate that PKC inhibition by inclusion of PKC19-36 in the patch pipette had no effect on AMPAR EPSC amplitude (Fig. $5 f)(108 \pm 14 \%$; $n=$ $6 ; p>0.05)$. However, inclusion of D609 in the patch pipette showed that PLC inhibition increased AMPAR EPSC amplitude (Fig. $5 d)(182 \pm 41 \% ; n=7 ; p<0.05)$. In this case, a stable baseline was achieved before application of OGD. These data indicate that both PLC and PKC play a role in mediating the depression of synaptic transmission following OGD.

Depression of synaptic transmission following OGD requires PICK1-mediated and dynamin-dependent AMPAR internalization

The protein PICK1 is critical for the removal of AMPARs from the synaptic membrane during LTD (Hanley, 2008; Terashima et 
a
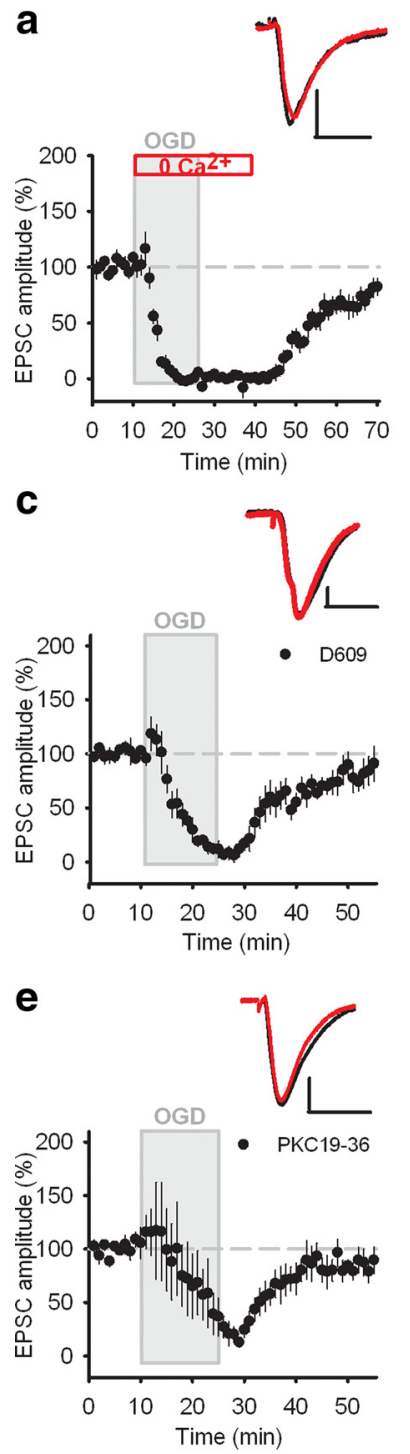

b
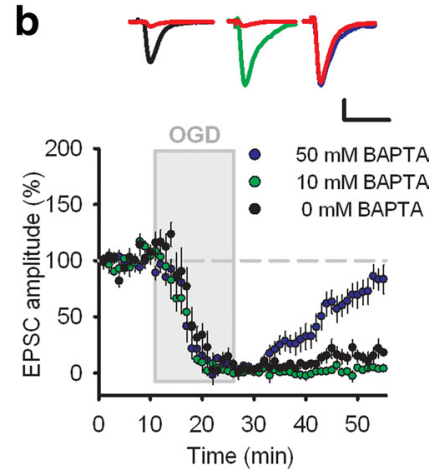

d

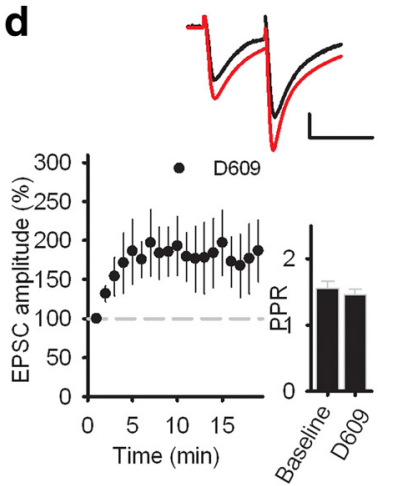

f
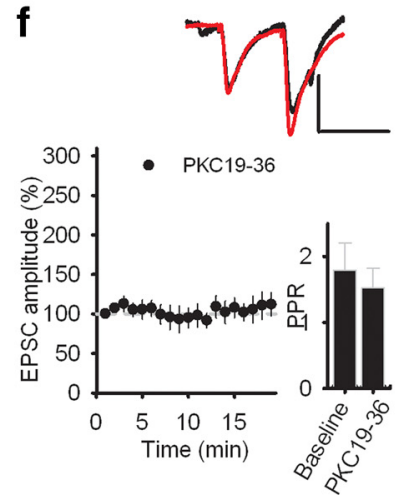

Figure 5. OGD-induced depression of AMPAR EPSCs requires intracellular $\mathrm{Ca}^{2+}, \mathrm{PLC}$, and PKC activation. $\boldsymbol{a}$, Removal of $\mathrm{Ca}^{2+}$ from aCSF during $0 G D$ and for a further 15 min prevented the depression of AMPAREPSCs. $\boldsymbol{b}$, Inclusion of $50 \mathrm{~mm}$ but not $10 \mathrm{~mm}$ BAPTA to the patch pipette prevented the depression of AMPAR EPSCS. C, Inclusion of the PLC inhibitor D609 (30 $\mu \mathrm{m})$ in the patch pipette prevented the depression of AMPAR EPSCs. $\boldsymbol{d}$, Inclusion of $30 \mu \mathrm{m}$ D609 in the patch pipette increased AMPAR EPSCs without changing PPR. $e$, Inclusion of the PKC inhibitory peptide PKC19-36 (4.8 $\mu \mathrm{m})$ in the patch pipette prevented the depression of AMPAR EPSCs. $\boldsymbol{f}$, Inclusion of $4.8 \mu \mathrm{M}$ PKC19-36 in the patch pipette had no effect on AMPAR EPSCs or PPR. The gray boxes indicate period of $O G D$. Example traces illustrate responses before (black, green, or blue) and 20-30 min following OGD (red). Calibration: 50 pA, 20 ms. Error bars indicate SEM.

al., 2008) and the switching of GluA2-containing to GluA2lacking receptors during OGD in CA1 pyramidal neurons (Dixon et al., 2009). Therefore, we next investigated whether PICK1 is important for the depression of synaptic transmission following OGD. The interaction between GluA2 and PICK1 is disrupted by the PDZ domain inhibitory peptides pep2-SVKI and pep2-EVKI, whereas the interaction between GluA2 and glutamate receptorinteracting protein (GRIP)/AMPA receptor-binding protein (ABP) (which also contain PDZ domains) is only disrupted by pep2-SVKI (Daw et al., 2000). Inclusion of pep2-SVKI (100 $\mu \mathrm{M})$ or pep2-EVKI $(100 \mu \mathrm{M})$ in the patch pipette prevented the depression of AMPAR EPSCs following OGD at AC synapses when compared with the control peptide pep2-SVKE (100 $\mu \mathrm{M})$, which

does not disrupt interactions with GluA2 (Fig. 6a) (pep2-SVKI, $61 \pm 13 \%, n=7, p<0.05$ compared with pep2-SVKE; pep2EVKI, $57 \pm 7 \%, n=9, p<0.001$ compared with pep2-SVKE; pep2-SVKE, $16 \pm 6 \%, n=7, p<0.05)$. Inclusion of pep2-SVKI or pep2-EVKI but not pep2-SVKE in the patch pipette produced an increase in AMPAR EPSC amplitude upon membrane rupture (Fig. $6 b-d$ ) (pep2-SVKI, $190 \pm 34 \%, n=8, p<0.01$; pep2-EVKI, $150 \pm 20 \%, n=6, p<0.05$; pep2-SVKE, $105 \pm 7 \%, n=8, p>$ $0.05)$. These results are similar to previous findings at CA1 Schaffer collateral synapses (Daw et al., 2000), although in this study no increase in EPSC amplitude was observed with pep2-EVKI peptide. In all cases, a stable baseline was achieved before application of OGD. Recovery of AMPAR EPSCs following OGD due to the addition of either pep2-SVKI or pep2-EVKI suggests that PICK1 rather than ABP/GRIP is a key mediator of EPSC depression. Incomplete recovery of AMPAR EPSCs following OGD, when the interaction between GluA2 and PICK1 is inhibited, suggests that PICK1-mediated removal of AMPARs from the postsynaptic membrane may not be the only mechanism for the depression of synaptic transmission or that the inhibitory peptides were not able to completely block the interaction with GluA2. Our experiments indicate that PICK1 is a mediator of AMPAR internalization following OGD at $\mathrm{AC}$ synapses.

Removal of AMPARs from the plasma membrane is thought to be mediated by dynamin-dependent endocytosis (Lüscher et al., 1999). Therefore, we next tested whether the removal of AMPARs following OGD is mediated by dynamin-dependent endocytosis. The interaction between dynamin and the $\mathrm{SH} 3$ domain of amphiphysin is disrupted by the inhibitory peptide P4 (Wigge et al., 1997; Kittler et al., 2000) with a similar action to the inhibitory peptide D15 (Lüscher et al., 1999). Inclusion of P4 (50 $\mu \mathrm{M})$ in the patch pipette caused an increase in AMPAR EPSC amplitude upon membrane rupture (Fig. $6 f)(231 \pm 45 \%$; $n=6$; $p<0.05)$ without any change in PPR $(116 \pm 5 \% ; p>0.05)$ and prevented the depression of AMPAR EPSCs following OGD (Fig. $6 e)(75 \pm 6 \% ; n=6 ; p>0.05)$. These data indicate that AMPAR internalization following OGD is mediated by dynamin-dependent endocytosis.

We also tested whether extrasynaptic as well as synaptic receptors were removed from the plasma membrane by dynamindependent endocytosis. We recorded current responses to application of exogenous glutamate $(10 \mathrm{~mm})$ to stimulate extrasynaptic and synaptic receptors directly while infusing the P4 inhibitory peptide via the recording pipette. Subsequent application of OGD produced no depression in responses (Fig. $6 g)(88 \pm 8 \% ; n=8 ; p>0.05)$, indicating that dynamindependent endocytosis is required for the removal of extrasynaptic AMPARs following OGD.

\section{OGD leads to a decrease of AMPAR protein levels specific to the $\mathrm{CA} 3$ region of the hippocampus}

To confirm that AMPARs are internalized from the plasma membrane following OGD, we performed surface biotinylations for GluA1 and GluA2. Hippocampal slices were either exposed to 15 min OGD or kept as control in aCSF containing oxygen and glucose. Thirty minutes following OGD, slices were labeled with biotin before the CA3 and CA1 regions were separated and subsequently processed for streptavidin chromatography and Western blotting. There was no difference in amounts of surface GluA1 or GluA2 subunits between OGD and controls within the CA1 region (Fig. 7a,b) (GluA1 OGD, $96 \pm 10 \%$, $n=6, p>0.05$; GluA2 OGD, $123 \pm 26 \%, n=6, p>0.05)$. 
a

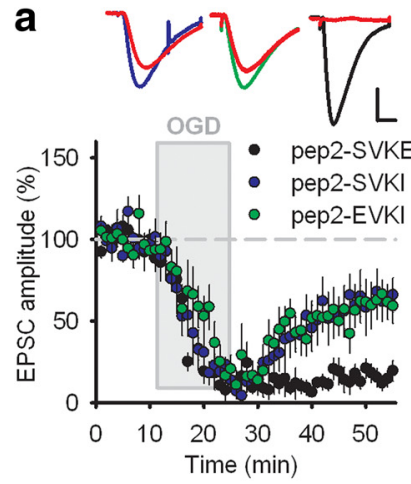

C
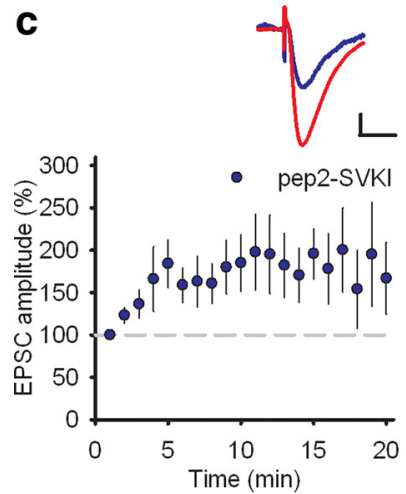

e
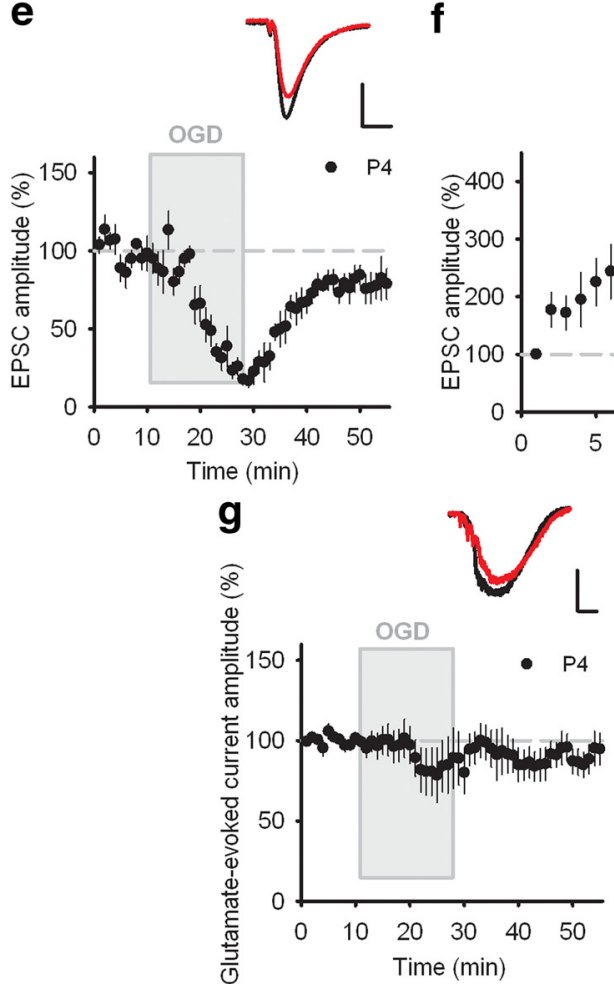

Figure 6. $O G D$ induces PICK1 and dynamin-dependent internalization of AMPARs. $\boldsymbol{a}$, Inclusion of either pep2-SVKI $(100 \mu \mathrm{m})$ or pep2-EVKI $(100 \mu \mathrm{m})$ but not pep2-SVKE $(100 \mu \mathrm{m})$ in the patch pipette prevented the depression of AMPAR EPSCs following OGD. Inclusion of $100 \mu \mathrm{M}$ SVKI (c) or EVKI (d) but not SVKE peptide (b) in the patch pipette increased AMPAR EPSCs. $\boldsymbol{e}$, Inclusion of the dynamin inhibitory peptide P4 $(50 \mu \mathrm{m})$ in the patch pipette prevented the depression of AMPAREPSCsfollowing OGD.f, Inclusion of the dynamin inhibitory peptide P4 (50 $\mu \mathrm{M}$ ) in the patch pipette increased AMPAREPSCs. $\boldsymbol{g}$, Inclusion of the dynamin inhibitory peptide P4 $(50 \mu \mathrm{m})$ in the patch pipette prevented the depression of glutamate-evoked (10 mM) responses following $0 G D$. The gray boxes indicate 15 min period of OGD. Example traces illustrate responses before (black, green, or blue) and 20-30 min following $0 G D$ or 10-15 min after beginning the experiment (red). Calibration: 50 pA, 10 or $200 \mathrm{~ms}(\boldsymbol{g})$. Error bars indicate SEM.
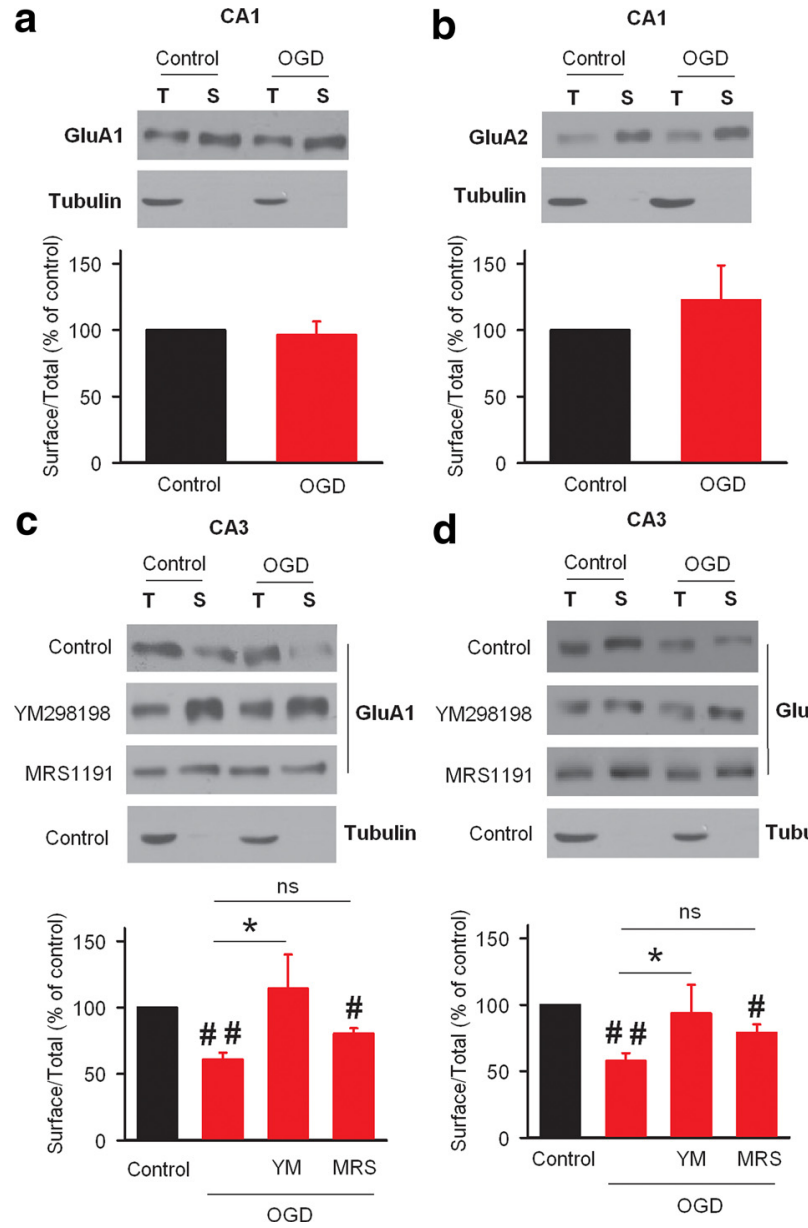

d

CA3
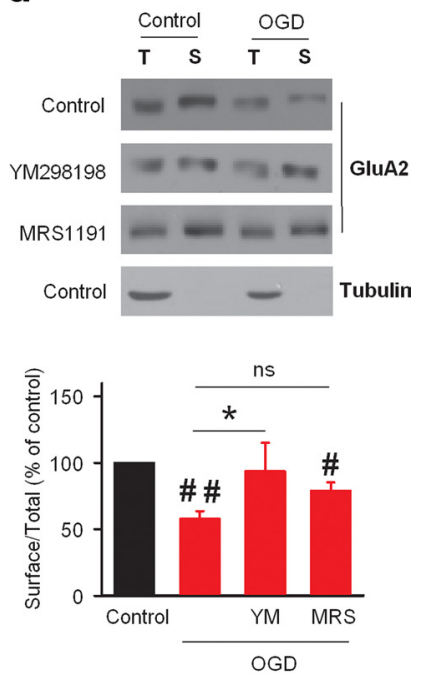

Figure 7. OGD leads to a decrease of surface AMPARs in the CA3 region. $\boldsymbol{a}, \boldsymbol{b}$, Surface GluA1 and GluA2 levels were decreased in CA3 but not CA1 following OGD. Control and OGD exposed slices were subject to surface biotinylation. The relative surface (S) and total (T) AMPARs was assessed by Western blot using specific antibodies against GluA1 and GluA2. Representative blots of 50\% total and 100\% surface GluA1 and GluA2 subunits and tubulin after OGD in CA1 region and $25 \%$ total and $100 \%$ surface in CA3 region. Graphs show the ratio of surface biotinylated to total AMPARs expressed as a percentage of control. $\boldsymbol{c}, \boldsymbol{d}$, Inhibition of mGluR1 or $A_{3}$ receptors prevented or attenuated the decrease in surface GluA1 and GluA2 in CA3 following OGD. Incubation of the slices in YM298198 and MRS1191 during OGD produced less internalization of AMPARs than control OGD-exposed slices. ${ }^{*} p<0.05$ and ns (not significant, $p=0.07$ for GluA1 and $p=0.05$ for GluA2) indicate statistical tests against control 0GD; ${ }^{*} p<0.05$ and $\# p<0.01$, significant difference to control in the absence of OGD. Error bars indicate SEM.

However, there was a reduction in surface GluA1 and GluA2 subunits within the $\mathrm{CA} 3$ region in slices that had received OGD (Fig. $7 c, d$ ) (GluA1 OGD, $61 \pm 5 \%, n=6, p<0.05$; GluA2 OGD, $58 \pm 6 \%, n=6, p<0.05)$.

mGluR1 and $\mathrm{A}_{3}$ receptors are both required for the removal of synaptic AMPARs following OGD (Figs. 2-4), so we tested whether their activation is also required for the reduction in surface levels of AMPAR subunits observed in the biotinylation assay. Hippocampal slices were subjected to 15 min OGD or control conditions in the presence of the mGluR1 antagonist YM298198 (50 nM) or the $A_{3}$ receptor antagonist MRS1191 (1 $\mu \mathrm{M})$, and surface biotinylations were performed. The mGluR1 antagonist prevented the reduction in surface GluA1 and GluA2 protein levels in the CA3 region following OGD (Fig. $7 c, d$ ) (GluA1 OGD, $114 \pm 10 \%, n=6, p>0.05$; GluA2 OGD, $94 \pm$ $9 \%, n=6, p>0.05)$, and the $\mathrm{A}_{3}$ receptor antagonist partially prevented the reduction in surface GluA1 and GluA2 (Fig. 7c,d) (GluA1 OGD, $80 \pm 3 \%, n=6, p<0.05$; GluA2 OGD, $79 \pm 6 \%$, 
a
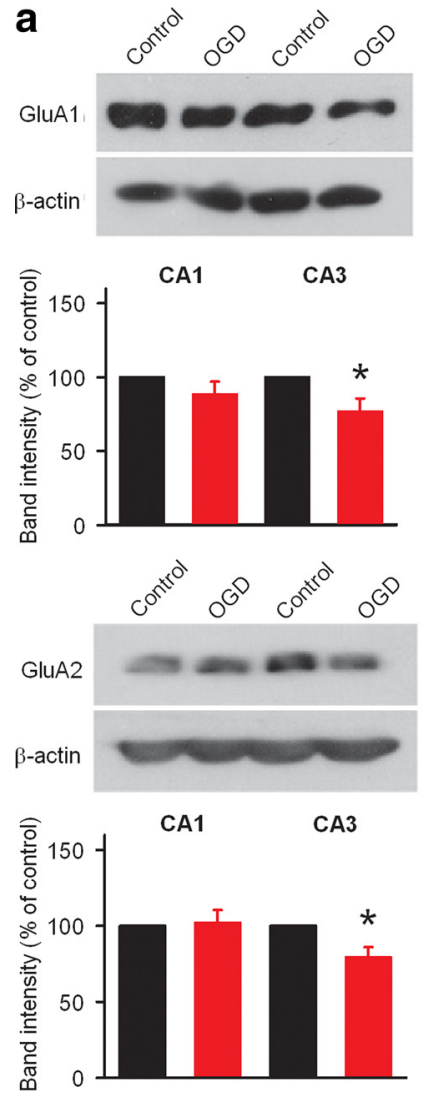

b
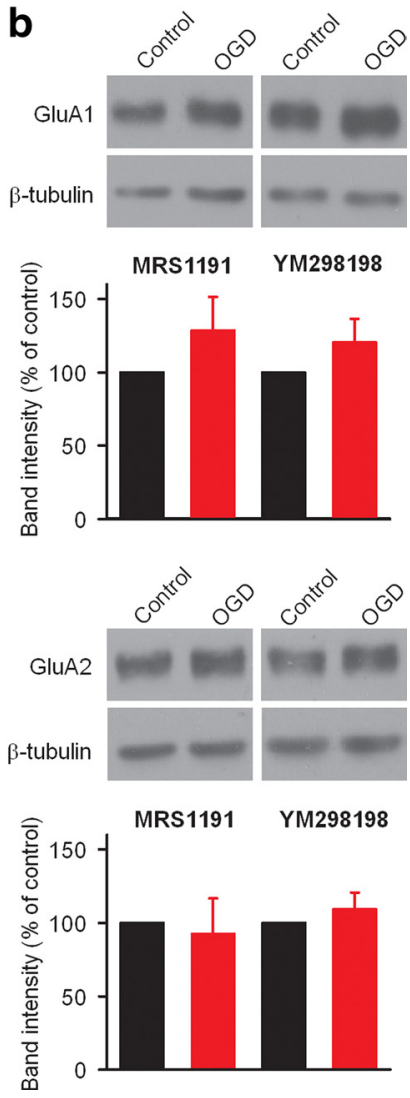

Figure 8. OGD leads to a decrease of AMPAR protein levels in the CA3 region. $\boldsymbol{a}$, Total GluA1 and GluA2 levels are decreased in CA3 but not CA1 following OGD. Western blots show GluA1 (top) and GluA2 (bottom) levels and their respective $\beta$-actin loading controls in CA1 and CA3 regions of control and OGD-exposed hippocampal slices. The graphs show pooled data expressed as percentage of $C A 1$ or $C A 3$ control. $\boldsymbol{b}$, Inhibition of $M G l u R 1$ or $A_{3}$ receptors prevented the decrease in GluA1 and GluA2 in CA3 following OGD. Western blots show GluA1 (top) and GluA2 (bottom) levels and their respective $\beta$-tubulin loading controls in CA3 region of control and OGD-exposed hippocampal slices treated with MRS1191 (1 $\mu \mathrm{M})$ or YM298198 (50 nM). Cumulative GluA1 and GluA2 results show quantified data from separate immunoblots. The graphs show pooled data expressed as percentage of MRS1191- or YM298198-treated slices without $0 \mathrm{GD}$. The asterisk $\left(^{*}\right)$ indicates significant difference to control $(p<0.05)$. Error bars indicate SEM.

$n=6, p<0.05)$. These results demonstrate that $\mathrm{mGluR} 1$ and $\mathrm{A}_{3}$ receptor activation is required for AMPAR removal from the plasma membrane in CA3 neurons following OGD.

AMPARs that are removed from the synaptic membrane may either be recycled back to the plasma membrane or targeted to lysosomes for degradation (Lee et al., 2004). We next tested whether AMPARs are degraded after being internalized. We investigated the fate of internalized AMPARs by quantifying total GluA1 and GluA2 expression $1 \mathrm{~h}$ after OGD. Hippocampal slices were either exposed to 15 min OGD or kept as control in aCSF containing oxygen and glucose. One hour following OGD, the $\mathrm{CA} 3$ and CA1 regions were separated, and then isolated and placed in lysis buffer for Western blotting analysis of the AMPAR subunits GluA1 and GluA2. There was no difference in total amounts of GluA1 or GluA2 subunits between OGD and controls within the CA1 region (Fig. $8 a$ ) (GluA1 OGD, $89 \pm 8 \%, n=8$, $p>0.05$; GluA2 OGD, $102 \pm 8 \%, n=9, p>0.05)$. However, there was a reduction in both GluA1 and GluA2 subunits within the CA3 region in slices that had received OGD (Fig. 8a) (GluA1 OGD, $76 \pm 10 \%, n=8, p<0.05$; GluA2 OGD, $79 \pm 7 \%, n=9$, $p<0.05)$. Both the mGluR1 antagonist and the $\mathrm{A}_{3}$ receptor an-

tagonist prevented the reduction in total GluA1 and GluA2 protein levels in the CA3 region following OGD (Fig. 8b) (GluA1 MRS1191 OGD, $128 \pm 23 \%, n=10, p>0.05$; GluA1 YM298198 OGD, $97 \pm 26 \%, n=10, p>0.05$; GluA2 MRS1 191 OGD, $120 \pm$ $16 \%, n=12, p>0.05$; GluA2 YM298198 OGD, $109 \pm 11 \%, n=$ $12, p>0.05)$. Together, these results demonstrate that mGluR1 and $A_{3}$ receptors are required for AMPAR removal from the plasma membrane and suggest they are subsequently degraded in CA3 pyramidal neurons following OGD.

\section{Discussion}

In this study, we demonstrate that OGD induces an almost complete depression of AMPAR-mediated synaptic transmission onto CA3 pyramidal neurons of the hippocampus. This effect in slices taken from young animals is caused by the coactivation of mGluR 1 and $A_{3}$ receptors together with a rise in intracellular calcium concentration leading to the removal of surface AMPARs.

The observed depression of AMPAR EPSCs following OGD could potentially result from a variety of sources, including depression of presynaptic action potentials, depression of presynaptic neurotransmitter release, or removal of postsynaptic receptors. We conclude the depression of synaptic transmission results from a removal of postsynaptic AMPARs for the following reasons: (1) presynaptic fiber volley does not decrease following OGD (Fig. 1c); (2) responses elicited by exogenous glutamate application are depressed by OGD (Fig. 1f); (3) NMDAR EPSCs recover following OGD (Fig. 1g); (4) specific manipulation of the postsynaptic environment by the introduction of BAPTA, PKC19-36, or D609 could reverse the depression of synaptic transmission (Fig. 5); (5) interfering with specific protein interactions known to regulate AMPAR internalization (PICK1 PDZ domain interactions and dynamin-amphiphysin interactions) prevents the depression of AMPAR-mediated synaptic transmission (Fig. 6). Furthermore, the involvement of PICK1 and dynamin in AMPAR EPSC depression suggests this event is an internalization of AMPARs mediated by endocytosis. This conclusion is supported by surface biotinylation data showing a decrease in the surface expression of GluA1 and GluA2 following OGD (Fig. 7).

Furthermore, the data suggest that internalization is followed by degradation of AMPAR subunits, which is selective to the CA3 hippocampal region (Fig. 8). Our electrophysiological data show a complete removal of AMPARs from CA3 neurons following OGD (Fig. 1), whereas the surface biotinylation data show only a $\sim 40 \%$ decrease (Fig. 7). This is perhaps not surprising since surface biotinylation will sample AMPARs on all cell types in CA3 including interneurons and glia (Bergles et al., 2000). We observe degradation of both GluA1 and GluA2 in the CA3 region $1 \mathrm{~h}$ following OGD. It is not currently clear whether all AMPARs are eventually degraded in CA3 pyramidal neurons following OGD or only the $\sim 30 \%$ that we show $1 \mathrm{~h}$ after OGD (Fig. 8). Our data suggest that OGD in CA3 results in a general endocytosis followed by degradation of AMPARs rather than switching between specific subunits as previously observed in the CA1 region (Noh et al., 2005; Dixon et al., 2009). Using biotinylation assays, we do not observe the OGD-dependent internalization of GluA2 in CA1 that we previously observed using electrophysiological techniques (Dixon et al., 2009). As discussed above, this could be explained by the contribution of AMPARs expressed on interneurons and glial cells to the biotinylation assay, masking the relatively subtle effect that might be expected following $15 \mathrm{~min}$ OGD in CA1 (Dixon et al., 2009). 
Activity-dependent plasticity of postsynaptic glutamate receptors in CA3 pyramidal neurons can be mediated by a variety of mechanisms. Long-term potentiation (LTP) of AMPAR EPSCs at AC synapses requires NMDAR activation but specifically not mGluR1 (Kobayashi and Poo, 2004), whereas LTD of AMPAR EPSCs at MF synapses requires $\mathrm{Ca}^{2+}$ influx through L-type $\mathrm{Ca}^{2+}$ channels instead of NMDAR or mGluR activation (Lei et al., 2003). This form of MF LTD requires the presence of PICK1, implying that AMPARs are removed from the synaptic membrane (Ho et al., 2009). LTD of kainate receptors at MF synapses also requires PICK1 as well as mGluR5 and PKC activation but not an increase in internal $\mathrm{Ca}^{2+}$ in a process that removes synaptic receptors from the plasma membrane (Selak et al., 2009). Finally, LTP of NMDARs at MF synapses requires activation of adenosine $\mathrm{A}_{2 \mathrm{~A}}$, NMDA, and mGluR5 receptors coupled to PKC activation (Kwon and Castillo, 2008; Rebola et al., 2008). Thus, evidence to date suggests there are multiple signaling pathways for the insertion or removal of glutamate receptors from the postsynaptic membrane in CA3 pyramidal neurons with common elements to many of them. The mechanisms for the removal of AMPARs following OGD demonstrated in this study illustrate that common intracellular pathways may be engaged during both synaptic plasticity and OGD.

Both mGluR1 and $A_{3}$ receptors couple to the $G_{q}$ subtype of G-protein (Nakamura et al., 1994; Abbracchio et al., 1995). Our data support a mechanism in which the $\mathrm{G}_{\mathrm{q}}$-coupled signaling pathway leads to activation of PLC, which cleaves PIP $_{2}$ into DAG and $\mathrm{IP}_{3}$. Activation of $\mathrm{IP}_{3}$ receptors on the endoplasmic reticulum causes release of intracellular $\mathrm{Ca}^{2+}$ stores while DAG activates PKC (Abbracchio et al., 1995). It has been shown that phosphorylation of GluA2 by PKC coupled with an increase in intracellular $\mathrm{Ca}^{2+}$ concentration promotes trafficking of GluA2 containing AMPARs by PICK1 (Xia et al., 2000; Perez et al., 2001; Hanley and Henley, 2005) and subsequent dynamin-dependent endocytosis. We propose this is the mechanism for the removal of AMPARs from the surface membrane, but our results do not indicate how the receptors are subsequently targeted for degradation rather than being recycled back to the plasma membrane (Lee et al., 2004).

Since mGluR1 and $A_{3}$ receptors both couple to the same $\mathrm{G}_{\mathrm{q}}$-initiated signaling pathway, this suggests the same pool of G-proteins are activated by each receptor. However, both mGluR1 and $\mathrm{A}_{3}$ receptors are required for the removal of AMPARs following OGD so mGluR1 activation should compensate for $A_{3}$ receptor stimulation and vice versa. Our data do not support this interpretation, implying that separate signaling pathways are used by each receptor. Alternatively, mGluR 1 and $\mathrm{A}_{3}$ receptors could form a more direct G-protein-independent interaction (Tabata et al., 2007).

Although supramaximal concentrations of agonists of either mGluR1 or $\mathrm{A}_{3}$ receptors alone can induce LTD in CA3, when we used lower submaximal concentrations we found that activation of both receptors at the same time produced LTD, whereas each on their own did not. This demonstrates a cooperative action between the two receptors, and when this was coupled with postsynaptic depolarization, which will produce calcium influx via voltage-dependent calcium channels, we were able to recapitulate the depression of synaptic transmission induced by OGD. This indicates that these three events are sufficient to cause the removal of AMPARs from the plasma membrane during OGD.

The removal of surface AMPARs from CA3 pyramidal neurons following $\mathrm{OGD}$ is antiexcitatory and could therefore reduce excitotoxicity in the hippocampus after ischemic insult. This provides mGluR1 and $\mathrm{A}_{3}$ receptors with a potentially critical role in regulating cell death following ischemia. The $\mathrm{A}_{3}$ receptor is suited to this role since its affinity for adenosine is low and will only be activated by the high levels of adenosine released during ischemia (Latini et al., 1999; von Lubitz et al., 1999). In addition, $A_{3}$ receptor activation has been shown to promote the recovery of synaptic responses following OGD in the CA1 region (Pugliese et al., 2006). However, reports are unclear and contrasting on the neuroprotective effects of $\mathrm{A}_{3}$ receptor activation during ischemia (von Lubitz et al., 1999). Activation of mGluR1 induces a postsynaptic LTD in CA1 pyramidal neurons mediated by PKC and PICK1 (Moult et al., 2006; Niehusmann et al., 2010), and there is also evidence that mGluR1 activation is neuroprotective (Kohara et al., 2008). Our data support a neuroprotective role for mGluR1 or $\mathrm{A}_{3}$ receptor activation.

The reasons why OGD-induced depression of synaptic transmission occurs in the CA3 but not CA1 region is unclear. Our data suggest the presence of adenosine $\mathrm{A}_{3}$ receptors could be a critical factor since $A_{3}$ receptor activation depressed synaptic transmission in CA3 but not in CA1 (Fig. 4). However, our data do not distinguish between a lack of $\mathrm{A}_{3}$ receptors in $\mathrm{CA} 1$ or a lack of the coupling between $\mathrm{A}_{3}$ receptors and AMPAR internalization. Of the other two necessary components to OGD-induced depression of synaptic transmission in CA3, mGluR1-mediated LTD (Moult et al., 2006; Lüscher and Huber, 2010) and OGDinduced depolarization and $\mathrm{Ca}^{2+}$ influx (Rossi et al., 2000, 2007) are both well documented in CA1 pyramidal neurons and are therefore unlikely to explain the observed difference in response to OGD between CA3 and CA1. An alternative possibility is local differences in the coupling of $A_{3}$ or mGluR1 receptors to their associated G-protein receptors.

Our data demonstrate clear differences in the response to OGD between CA3 and CA1 pyramidal neurons that support previous findings that $\mathrm{CA} 3$ neurons are much better equipped to survive ischemic trauma than CA1 neurons. Understanding the mechanisms that enable $\mathrm{CA} 3$ neurons to have a greater resistance to ischemic damage than CA1 neurons could potentially inform future neuroprotective strategies.

\section{References}

Aarts M, Liu Y, Liu L, Besshoh S, Arundine M, Gurd JW, Wang YT, Salter MW, Tymianski M (2002) Treatment of ischemic brain damage by perturbing NMDA receptor-PSD-95 protein interactions. Science 298: $846-850$.

Abbracchio MP, Brambilla R, Ceruti S, Kim HO, von Lubitz DK, Jacobson KA, Cattabeni F (1995) G protein-dependent activation of phospholipase $C$ by adenosine $A_{3}$ receptors in rat brain. Mol Pharmacol 48:1038-1045.

Bergles DE, Roberts JD, Somogyi P, Jahr CE (2000) Glutamatergic synapses on oligodendrocyte precursor cells in the hippocampus. Nature 405: 187-191.

Butler TR, Self RL, Smith KJ, Sharrett-Field LJ, Berry JN, Littleton JM, Pauly JR, Mulholland PJ, Prendergast MA (2010) Selective vulnerability of hippocampal cornu ammonis 1 pyramidal cells to excitotoxic insult is associated with the expression of polyamine-sensitive $N$-methyl-Dasparate-type glutamate receptors. Neuroscience 165:525-534.

Choi DW (1995) Calcium: still center-stage in hypoxic-ischemic neuronal death. Trends Neurosci 18:58-60.

Cimarosti H, Henley JM (2008) Investigating the mechanisms underlying neuronal death in ischemia using in vitro oxygen-glucose deprivation: potential involvement of protein SUMOylation. Neuroscientist 14: $626-636$.

Cronberg T, Jensen K, Rytter A, Wieloch T (2005) Selective sparing of hippocampal CA3 cells following in vitro ischemia is due to selective inhibition by acidosis. Eur J Neurosci 22:310-316.

Cunha RA, Johansson B, van der Ploeg I, Sebastião AM, Ribeiro JA, Fredholm BB (1994) Evidence for functionally important adenosine A2a receptors in the rat hippocampus. Brain Res 649:208-216. 
Daw MI, Chittajallu R, Bortolotto ZA, Dev KK, Duprat F, Henley JM, Collingridge GL, Isaac JT (2000) PDZ proteins interacting with C-terminal GluR2/3 are involved in a PKC-dependent regulation of AMPA receptors at hippocampal synapses. Neuron 28:873-886.

Dixon AK, Gubitz AK, Sirinathsinghji DJ, Richardson PJ, Freeman TC (1996) Tissue distribution of adenosine receptor mRNAs in the rat. Br J Pharmacol 118:1461-1468.

Dixon RM, Mellor JR, Hanley JG (2009) PICK1-mediated glutamate receptor subunit 2 (GluR2) trafficking contributes to cell death in oxygen/ glucose-deprived hippocampal neurons. J Biol Chem 284:14230-14235.

Dunwiddie TV, Masino SA (2001) The role and regulation of adenosine in the central nervous system. Annu Rev Neurosci 24:31-55.

Frantseva MV, Carlen PL, El-Beheiry H (1999) A submersion method to induce hypoxic damage in organotypic hippocampal cultures. J Neurosci Methods 89:25-31.

Gorter JA, Petrozzino JJ, Aronica EM, Rosenbaum DM, Opitz T, Bennett MV, Connor JA, Zukin RS (1997) Global ischemia induces downregulation of Glur2 mRNA and increases AMPA receptor-mediated $\mathrm{Ca}^{2+}$ influx in hippocampal CA1 neurons of gerbil. J Neurosci 17:6179-6188.

Hanley JG (2008) PICK1: a multi-talented modulator of AMPA receptor trafficking. Pharmacol Ther 118:152-160.

Hanley JG, Henley JM (2005) PICK1 is a calcium-sensor for NMDAinduced AMPA receptor trafficking. EMBO J 24:3266-3278.

Hansen AJ (1985) Effect of anoxia on ion distribution in the brain. Physiol Rev 65:101-148.

Hardingham GE (2009) Coupling of the NMDA receptor to neuroprotective and neurodestructive events. Biochem Soc Trans 37:1147-1160.

Ho MT, Pelkey KA, Pelletier JG, Huganir RL, Lacaille JC, McBain CJ (2009) Burst firing induces postsynaptic LTD at developing mossy fibre-CA3 pyramid synapses. J Physiol 587:4441-4454.

Joshi I, Andrew RD (2001) Imaging anoxic depolarization during ischemialike conditions in the mouse hemi-brain slice. J Neurophysiol 85:414-424.

Kamiya H, Shinozaki H, Yamamoto C (1996) Activation of metabotropic glutamate receptor type $2 / 3$ suppresses transmission at rat hippocampal mossy fibre synapses. J Physiol 493:447-455.

Kass IS, Lipton P (1986) Calcium and long-term transmission damage following anoxia in dentate gyrus and CA1 regions of the rat hippocampal slice. J Physiol 378:313-334.

Kirino T, Tamura A, Sano K (1985) Selective vulnerability of the hippocampus to ischemia-reversible and irreversible types of ischemic cell damage. Prog Brain Res 63:39-58.

Kittler JT, Delmas P, Jovanovic JN, Brown DA, Smart TG, Moss SJ (2000) Constitutive endocytosis of GABAA receptors by an association with the adaptin AP2 complex modulates inhibitory synaptic currents in hippocampal neurons. J Neurosci 20:7972-7977.

Kobayashi K, Poo MM (2004) Spike train timing-dependent associative modification of hippocampal CA3 recurrent synapses by mossy fibers. Neuron 41:445-454.

Kohara A, Takahashi M, Yatsugi S, Tamura S, Shitaka Y, Hayashibe S, Kawabata S, Okada M (2008) Neuroprotective effects of the selective type 1 metabotropic glutamate receptor antagonist YM-202074 in rat stroke models. Brain Res 1191:168-179.

Kwon HB, Castillo PE (2008) Long-term potentiation selectively expressed by NMDA receptors at hippocampal mossy fiber synapses. Neuron 57:108-120.

Latini S, Pedata F (2001) Adenosine in the central nervous system: release mechanisms and extracellular concentrations. J Neurochem 79:463-484.

Latini S, Bordoni F, Pedata F, Corradetti R (1999) Extracellular adenosine concentrations during in vitro ischaemia in rat hippocampal slices. Br J Pharmacol 127:729-739.

Lee SH, Simonetta A, Sheng M (2004) Subunit rules governing the sorting of internalized AMPA receptors in hippocampal neurons. Neuron 43:221-236.

Lei S, Pelkey KA, Topolnik L, Congar P, Lacaille JC, McBain CJ (2003) Depolarization-induced long-term depression at hippocampal mossy fiber-CA3 pyramidal neuron synapses. J Neurosci 23:9786-9795.

Lipton P (1999) Ischemic cell death in brain neurons. Physiol Rev 79: $1431-1568$.

Liu S, Lau L, Wei J, Zhu D, Zou S, Sun HS, Fu Y, Liu F, Lu Y (2004) Expression of $\mathrm{Ca}^{2+}$-permeable AMPA receptor channels primes cell death in transient forebrain ischemia. Neuron 43:43-55.
Lüscher C, Huber KM (2010) Group 1 mGluR-dependent synaptic longterm depression: mechanisms and implications for circuitry and disease. Neuron 65:445-459.

Lüscher C, Xia H, Beattie EC, Carroll RC, von Zastrow M, Malenka RC, Nicoll RA (1999) Role of AMPA receptor cycling in synaptic transmission and plasticity. Neuron 24:649-658.

Martone ME, Hu BR, Ellisman MH (2000) Alterations of hippocampal postsynaptic densities following transient ischemia. Hippocampus 10:610-616.

Moult PR, Gladding CM, Sanderson TM, Fitzjohn SM, Bashir ZI, Molnar E, Collingridge GL (2006) Tyrosine phosphatases regulate AMPA receptor trafficking during metabotropic glutamate receptor-mediated long-term depression. J Neurosci 26:2544-2554.

Nakamura K, Nukada T, Haga T, Sugiyama H (1994) G protein-mediated inhibition of phosphoinositide metabolism evoked by metabotropic glutamate receptors in frog oocytes. J Physiol 474:35-41.

Newell DW, Malouf AT, Franck JE (1990) Glutamate-mediated selective vulnerability to ischemia is present in organotypic cultures of hippocampus. Neurosci Lett 116:325-330.

Niehusmann P, Seifert G, Clark K, Atas HC, Herpfer I, Fiebich B, Bischofberger J, Normann C (2010) Coincidence detection and stress modulation of spike time-dependent long-term depression in the hippocampus. J Neurosci 30:6225-6235.

Noh KM, Yokota H, Mashiko T, Castillo PE, Zukin RS, Bennett MV (2005) Blockade of calcium-permeable AMPA receptors protects hippocampal neurons against global ischemia-induced death. Proc Natl Acad Sci U S A 102:12230-12235.

Opitz T, Grooms SY, Bennett MV, Zukin RS (2000) Remodeling of $\alpha$-amino-3-hydroxy-5-methyl-4-isoxazole-propionic acid receptor subunit composition in hippocampal neurons after global ischemia. Proc Natl Acad Sci U S A 97:13360-13365.

Palmer TM, Gettys TW, Stiles GL (1995) Differential interaction with and regulation of multiple G-proteins by the rat $\mathrm{A}_{3}$ adenosine receptor. J Biol Chem 270:16895-16902.

Pellegrini-Giampietro DE, Zukin RS, Bennett MV, Cho S, Pulsinelli WA (1992) Switch in glutamate receptor subunit gene expression in CA1 subfield of hippocampus following global ischemia in rats. Proc Natl Acad Sci U S A 89:10499-10503.

Perez JL, Khatri L, Chang C, Srivastava S, Osten P, Ziff EB (2001) PICK1 targets activated protein kinase $\mathrm{C} \alpha$ to AMPA receptor clusters in spines of hippocampal neurons and reduces surface levels of the AMPA-type glutamate receptor subunit 2. J Neurosci 21:5417-5428.

Popa-Wagner A, Carmichael ST, Kokaia Z, Kessler C, Walker LC (2007) The response of the aged brain to stroke: too much, too soon? Curr Neurovasc Res 4:216-227.

Pugliese AM, Coppi E, Spalluto G, Corradetti R, Pedata F (2006) A A adenosine receptor antagonists delay irreversible synaptic failure caused by oxygen and glucose deprivation in the rat CAl hippocampus in vitro. $\mathrm{Br} \mathrm{J}$ Pharmacol 147:524-532.

Pulsinelli WA (1985) Selective neuronal vulnerability: morphological and molecular characteristics. Prog Brain Res 63:29-37.

Rebola N, Rodrigues RJ, Lopes LV, Richardson PJ, Oliveira CR, Cunha RA (2005) Adenosine A1 and A2A receptors are co-expressed in pyramidal neurons and co-localized in glutamatergic nerve terminals of the rat hippocampus. Neuroscience 133:79-83.

Rebola N, Lujan R, Cunha RA, Mulle C (2008) Adenosine A2A receptors are essential for long-term potentiation of NMDA-EPSCs at hippocampal mossy fiber synapses. Neuron 57:121-134.

Rossi DJ, Oshima T, Attwell D (2000) Glutamate release in severe brain ischaemia is mainly by reversed uptake. Nature 403:316-321.

Rossi DJ, Brady JD, Mohr C (2007) Astrocyte metabolism and signaling during brain ischemia. Nat Neurosci 10:1377-1386.

Selak S, Paternain AV, Aller MI, Picó E, Rivera R, Lerma J (2009) A role for SNAP25 in internalization of kainate receptors and synaptic plasticity. Neuron 63:357-371.

Silver IA, Erecinska M (1990) Intracellular and extracellular changes of $\left[\mathrm{Ca}^{2+}\right]$ in hypoxia and ischemia in rat brain in vivo. J Gen Physiol 95:837-866.

Simon RP, Swan JH, Griffiths T, Meldrum BS (1984) Blockade of N-methyl$\mathrm{D}$-aspartate receptors may protect against ischemic damage in the brain. Science 226:850-852.

Stanika RI, Winters CA, Pivovarova NB, Andrews SB (2010) Differential 
NMDA receptor-dependent calcium loading and mitochondrial dysfunction in CA1 vs. CA3 hippocampal neurons. Neurobiol Dis 37:403-411.

Sun X, Yao H, Douglas RM, Gu XQ, Wang J, Haddad GG (2010) Insulin/ PI3K signaling protects dentate neurons from oxygen-glucose deprivation in organotypic slice cultures. J Neurochem 112:377-388.

Swanson TH, Drazba JA, Rivkees SA (1995) Adenosine $A_{1}$ receptors are located predominantly on axons in the rat hippocampal formation. J Comp Neurol 363:517-531.

Tabata T, Kawakami D, Hashimoto K, Kassai H, Yoshida T, Hashimotodani Y, Fredholm BB, Sekino Y, Aiba A, Kano M (2007) G proteinindependent neuromodulatory action of adenosine on metabotropic glutamate signalling in mouse cerebellar Purkinje cells. J Physiol 581:693-708.

Terashima A, Pelkey KA, Rah JC, Suh YH, Roche KW, Collingridge GL, McBain CJ, Isaac JT (2008) An essential role for PICK1 in NMDA receptor-dependent bidirectional synaptic plasticity. Neuron 57: 872-882.

Tsubokawa H, Oguro K, Robinson HP, Masuzawa T, Kirino T, Kawai N
(1992) Abnormal $\mathrm{Ca}^{2+}$ homeostasis before cell death revealed by whole cell recording of ischemic CAl hippocampal neurons. Neuroscience 49:807-817.

Tsubokawa H, Oguro K, Masuzawa T, Kawai N (1994) $\mathrm{Ca}^{2+}$-dependent non-NMDA receptor-mediated synaptic currents in ischemic CA1 hippocampal neurons. J Neurophysiol 71:1190-1196.

von Lubitz DK, Ye W, McClellan J, Lin RC (1999) Stimulation of adenosine $\mathrm{A}_{3}$ receptors in cerebral ischemia. Neuronal death, recovery, or both? Ann N Y Acad Sci 890:93-106.

Wigge P, Vallis Y, McMahon HT (1997) Inhibition of receptor-mediated endocytosis by the amphiphysin SH3 domain. Curr Biol 7:554-560.

Xia J, Chung HJ, Wihler C, Huganir RL, Linden DJ (2000) Cerebellar longterm depression requires PKC-regulated interactions between GluR2/3 and PDZ domain-containing proteins. Neuron 28:499-510.

Yin HZ, Sensi SL, Ogoshi F, Weiss JH (2002) Blockade of $\mathrm{Ca}^{2+}$-permeable AMPA/kainate channels decreases oxygen-glucose deprivation-induced $\mathrm{Zn}^{2+}$ accumulation and neuronal loss in hippocampal pyramidal neurons. J Neurosci 22:1273-1279. 